\title{
II. Die Refrigerien unter S. Sebastiano: Heiligen- und Totenmemoria als Gemeinschaft der Lebenden und der Toten
}

Die Frage nach der Relation von Heiligenerinnerung und kollektiver Identität ist nicht gleichbedeutend mit einer Geschichte der Heiligenverehrung im kaiserzeitlichen und spätantiken Rom. Zwei der ältesten Orte stadtrömischer Heiligenerinnerung - die Petrusmemoria unter der vatikanischen Petrusbasilika und die sogenannte Papstgruft in der area I des Kallixtcoemeteriums erlauben keine hinreichenden Aufschlüsse darüber, in welcher Weise die Heiligen dort zu Kristallisationspunkten von Prozessen kollektiver Identitätsstiftung wurden. Die bei den Grabungen während der 1940er Jahre unter der Vatikanbasilika entdeckte aedicula, die um das Jahr 160 n. Chr. im Hof einer antiken Nekropole errichtet wurde, ${ }^{1}$ hat vor allem Zündstoff für Diskussionen über die Historizität eines Petrusgrabs am Vatikan geliefert, darüber hinaus jedoch keine tieferen Einblicke in die Rolle dieses Ortes für die Petrusverehrung gewährt: Die wenigen Indizien - vor allem die prominente Rolle der Christusmonogramme unter den dort gefundenen Graffiti - legen nahe, dass die Nekropole am Vatikan als Kultzentrum erst relativ spät an Popularität gewann; ${ }^{2}$ nennenswerte Rückschlüsse auf Formen der kultischen Verehrung, den Grad ihrer Institutionalisierung, die soziale Struktur der Teilnehmer und deren Haltungen gegenüber dem kommemorierten Apostel erlauben sie nicht. ${ }^{3}$

1 Die Ergebnisse der Grabungen sind dokumentiert in den Esplorazioni (= Apollonj Ghetti u. a. 1951). Zu den von 1940 bis 1949 durchgeführten Grabungen und zu der umfangreichen archäologischen Diskussion um die Verehrungsstätte des Petrus am Vatikan vgl. die jüngste Bilanz von Thümmel 1999, 15-72.

2 Die Monogramme verweisen auf die Anbringung der Graffiti erst in konstantinischer Zeit, vgl.

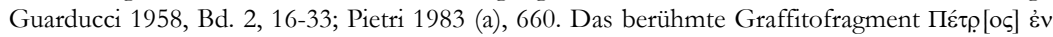
i [ fung Petri gedeutet (vgl. zuletzt Thümmel 1999, 70f.); auch hier erscheint eine sichere Datierung in die vorkonstantinische Zeit nicht möglich.

3 Lampe 21989, 82-94 entfaltet um den archäologischen Befund am Vatikan eine Reihe haltloser Spekulationen zur Sozialgeschichte der römischen Gemeinde des 2. Jh., die, ebenso wie seine auf der topographischen Verteilung der römischen Titelkirchen und Grabareale und auf der legendarischen Überlieferung der Märtyrerakten basierenden Schlussfolgerungen zur geographischen Verteilung der Christen und ihrer sozialen Zusammensetzung, einer gesicherten Grundlage ent- 
Etwas anders verhält es sich mit der area I des Kallixtcoemeteriums, die von der Forschung als erste kollektive Grablege der römischen Gemeinde interpretiert wird, ${ }^{4}$ und in deren unterirdischem Gangsystem sich das cubiculum $\mathrm{L}^{1}$ befindet, eine Grabkammer, die als eine sequentielle Grablege für mindestens neun aufeinander folgende römische Bischöfe von Pontian (230235) bis Eutychian (275-283) diente. ${ }^{5}$ Im Unterschied zur vatikanischen Nekropole eröffnet der Kontext der bischöflichen Grablege an der via Appia den Raum für begründetere Hypothesen bezüglich der identitätsstiftenden Dimension der Anlage. So lässt sich der in der Papstgruft monumentalisierte Gedanke bischöflicher Traditions- und Sukzessionsbildung, der wohl nicht erst seit dem 2. Drittel des 3. Jh., sondern bereits um 200 in der area I des Kallixtcoemeteriums sichtbare Gestalt gewann, ${ }^{6}$ in unmittelbare Beziehung

behren (ebd., 10-52). Gegen den Umgang Lampes mit den literarischen Quellen lassen sich vergleichbare methodische Einwände erheben (vgl. Schöllgen 1989).

4 Die Deutung geht auf Giovanni B. de Rossi zurück und ist in unterschiedlichen Akzentuierungen (Armen-, Klerikerfriedhof) von der Forschung weitgehend akzeptiert worden; vgl. u. a. Gülzow 1969, 167; zuletzt Fiocchi Nicolai 1997, 123; dens. 2003, 380-382. Skeptisch gegenüber der Existenz einer derartigen Gemeindegrablege in Rom ist Rebillard 1993, 988-995; ders. 1997, 743f., 747-749. Seine Einwände sind jedoch nicht überzeugend: Die Tatsache, dass sich im 3. und 4. Jh. zahlreiche Christen nicht in solchen Gemeindegrablegen, sondern in paganen Nekropolen und Grablegen (vgl. Johnson 1997) bzw. in Familienmausoleen bestatten ließen, spricht nicht gegen die Annahme, dass die römische Gemeinde als Eigentümerin über Grabareale verfügte, die sie für bestimmte Gemeindemitglieder (Arme, Kleriker) zur Verfügung stellte; das von Rebillard zugrunde gelegte Modell eines hochmittelalterlichen Pfarrkirchenfriedhofs als alleiniger Grablege, auf die sich die Bestattungen von Gemeindemitgliedern ausschließlich konzentrierten, ist anachronistisch. - Grundlegend für die archäologischen Fragen zu den unterirdischen Bereichen der area I des Kallixtcoemeteriums sind immer noch de Rossi 18641877, Bd. 2 und besonders Styger 1925-1926, vgl. ferner Picard 1969, 728-733; Borgolte 21995 , 21-37; Spera 1999, 124-127, $378 f$.

5 Einzig Cornelius (251-253), der im Exil in Centumcellae starb, wurde erst später nach Rom überführt und in einem anderen Teil des Kallixtcoemeteriums, der sogenannten Lucinaregion, beigesetzt (vgl. Brandenburg 1968/1969). Rebillard 1993, 992f. (ebenso bereits Duchesne [1886], in: LP I, XCIIIf. und 143, Anm. 5) meint, dass bereits Bischof Urban (222-230) in der Papstgruft beigesetzt worden sei, da in der Kammer ein Inschriftenfragment mit der Aufschrift OYPBANO $\Sigma$ Е[лі́бколо $\varsigma]$ gefunden wurde und der Name Urbanus in einer Inschriftentafel erschien, auf der Sixtus III. (432-440) die in der Papstgruft Bestatteten auflistete, und die am Eingang der Papstgruft angebracht wurde. Dies ist überzeugender als die von de Rossi begründete Hypothese, in diesem Urbanus einen auswärtigen Bischof zu sehen, der in der römischen Bischofsgruft beigesetzt wurde, und das Grab des römischen Bischofs Urbanus im Praetextatuscoemeterium zu lokalisieren (so Picard 1969, 730; Borgolte 21995, 24): Diese Auffassung kann sich nur auf das unsichere Zeugnis der späteren hagiographischen Tradition stützen, die Passio Caeciliae, von der auch der Eintrag im Liber Pontificalis abhängt (LP I, 62/143).

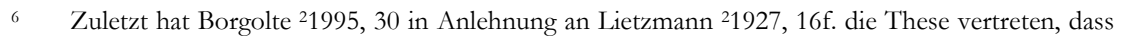
die Papstgruft erst unter Fabian (236-250) zu einer sequentiellen Bischofsgrablege geworden sei, und die Entstehung der Anlage als Reaktion auf eine Sukzessionskrise innerhalb der römischen Gemeinde gedeutet, die durch den Konflikt der Bischöfe Zephyrin (199-217) und Kallixt (217222) mit der Schule des Presbyters Hippolytos ausgelöst und durch das gemeinsame Exil von Pontian (230-235) und Hippolytos beigelegt worden sei (vgl. auch u., S. 217). Es gibt jedoch deutliche Hinweise darauf, dass bereits die Bischöfe Victor I. (189-199) und Zephyrin in oberir- 
zur Funktion der Anlage als Grablege der römischen Gemeinde setzen: Der Aufbau gemeindeeigener und auf den Bischof als Spitze der Gemeinde verweisender Strukturen, wie sie der kollektive Grabbezirk an der via Appia darstellt, und die Akzentuierung des bischöflichen Traditions- und Sukzessionsgedankens sind als zwei eng aufeinander bezogene Formen monepiskopaler und monarchischer ${ }^{7}$ Institutionenbildung aufzufassen. Das coemeterium an der via Appia wurde damit zu einem Ort, an dem die Identität der römischen ecclesia als Bischofsgemeinde auf unterschiedlichen Ebenen symbolisch vermittelt wurde - ein Vorgang, für den Erinnerungsbezüge an die verstorbenen Gemeindemitglieder bzw. die Vorgängerbischöfe eine konstitutive Rolle spielten. Obwohl demnach die area I des Kallixtcoemeteriums für die hier interessierende Thematik unmittelbar einschlägig ist, fehlt es jedoch auch beim coemeterium an der via Appia - darin der Petrusmemoria am Vatikan vergleichbar - an Anhaltspunkten, die dem äußeren Befund einer durch Gedenken und Erinnerungstopographie vermittelten Identität ein tiefenschärferes Profil verleihen würden: Über eine Reihe von kalendarischen Kommemorationsdaten von Bischöfen des 3. Jh. ${ }^{8}$ hinaus lässt sich nur wenig dazu sagen, in welcher Weise sich das Bischofsgedenken vollzog und durch das Gedenken an die verstorbenen Gemeindemitglieder Prozesse kollektiver Identitätsstiftung in Gang gesetzt wurden.

Anders verhält es sich mit der sogenannten „Triklia“ an der via Appia, einem Komplex, der in den Jahren 1915 und 1916 bei Grabungen unter der Basilika von S. Sebastiano entdeckt wurde, und der das Bild von der Geschichte der Apostelverehrung in Rom und von den Praktiken der Heiligenverehrung im 3. Jh. einschneidend verändert hat. ${ }^{9}$ Die Basilika war über einer älteren christlichen Kultanlage errichtet worden, einem Hof mit einer Grundfläche in Form eines unregelmäßigen Vierecks von etwa $360 \mathrm{~m}^{2}$, der in eine Reihe von umliegenden Grabmälern und Totenkultanlagen eingebettet war,

dischen Teilen der area I bestattet worden sind; für Urban (222-235) vgl. die vorige Anmerkung. Da von den römischen Bischöfen ab Victor I. demnach nur Kallixt (217-222) nicht in der area I bestattet wurde, fungierte die area I des Kallixtcoemeteriums vermutlich bereits seit ihrer Gründung um 200 zugleich als Gemeinde- und als Bischofsgrablege. - Zur Beisetzung von Zephyrin in einer der beiden Trikonchen der area I, die sich im oberirdischen Bereich der Anlage befanden, vgl. Spera 1999, 113f. Der Nachweis, dass auch das Grab Victors I. im Bereich der area I zu suchen ist, würde an dieser Stelle zu weit führen; die Frage soll demnächst in einem separaten Aufsatz behandelt werden.

7 Zur Differenzierung zwischen Monepiskopat und monarchischem Episkopat vgl. Schöllgen 1986.

8 Überliefert in der depositio episcoporum und der depositio martyrum des Chronographen von 354.

$9 \quad \mathrm{Zu}$ den Anlagen unter S. Sebastiano vgl. Tolotti 1953, 54-221; Jastrzebowska 1981, 14-113; Kjærgaard 1984; Spera 1999, 209-225. 
die noch bis in das 3. Jh. n. Chr. für Bestattungen genutzt wurden. ${ }^{10}$ Auch der - seit seiner Entdeckung in der Forschung als "Triklia“ bezeichnete - Hof erfüllte eine entsprechende Funktion. Er erhob sich über einer älteren Grabanlage, einem aufgelassenen Arenar, dessen Gänge wohl frühestens seit der ersten Hälfte des 2. Jh. mit Gräbern belegt wurden. Ein Teil dieses Arenars brach später ein und bildete eine Senke (die sogenannte ,piazzola“), in deren Wände in antoninischer Zeit drei Mausoleen eingelassen wurden. Mehrere dicht beieinander liegende Inschriften in einem Hypogäum, das von einem dieser Mausoleen abgeht, erwähnen die Kaisernamen des turbulenten Mehrkaiserjahrs 238: die beiden Gordiane, Pupienus und Balbinus. ${ }^{11}$ Diese Inschriften stellen den jüngsten Beleg für die Nutzung der Mausoleen und ihrer Hypogäen dar, bevor die „piazzola“ zugeschüttet und über ihr der Trikliakomplex angelegt wurde. ${ }^{12}$

Dieser Hof weist mehrere Charakteristika auf, die seine Nutzung als eine Totenkultanlage wahrscheinlich machen. Die Ausstattung der Triklia mit Bänken, einem Brunnen und einer Zisterne entspricht vergleichbaren Einrichtungen in Verbindung mit Grabanlagen, die für Versammlungen der Grabbesucher und gemeinsame Mähler bestimmt waren. ${ }^{13}$ Die Abhaltung von Mählern wird ebenfalls bestätigt durch die Graffiti, die die Besucher in die Wände der Triklia eingeritzt haben: Sie bezeugen, dass Christen in der Triklia Mahlfeiern (refrigeria) für die Apostel Petrus und Paulus begingen. Gesicherte Hinweise auf eine Datierung enthalten die Graffiti nicht. Zwar glaubte Robert Marichal in einem Graffito eine Konsulardatierung des Jahres $260 \mathrm{zu}$ erkennen, doch ist seine Lesung in der Forschung nicht unbestritten geblieben und lässt sich daher nicht als Datierungskriterium heranziehen. ${ }^{14}$

$10 \quad \mathrm{Zu}$ den Abmessungen des Trikliahofes vgl. Jastrzebowska 1981, 67; eine Rekonstruktionszeichnung bietet Tolotti 1953, 167, fig. 40. Die umliegenden Anlagen (Straße mit zwei Kolumbarienreihen, ,villa piccola“, „villa grande“) werden ausführlich diskutiert von Jastrzebowska 1981, 1441, vgl. ferner Spera 1999, 209-219. Die ,villa piccola“ wurde erst im 3. Jh. als monumentaler Eingang zur Kolumbarienstraße angelegt; die „villa grande“ diente vermutlich - ähnlich wie die Triklia - als Versammlungsort für den Totenkult. Die ersten Kolumbarien wurden bereits im 1. Jh. n. Chr. errichtet; eine spätere durchgehende Nutzung der Kolumbarien und der beiden „villae“ (vermutlich bis zur Errichtung der basilica apostolorum) ist belegt durch Körperbestattungen in einigen Kolumbarien sowie durch die Dekoration der ,villae“.

11 Jastrzebowska 1981, 55. Die tituli sind offenbar nicht mehr vorhanden; vgl. den Kommentar von Alföldy zu CIL VI, 40689.

12 Jastrzebowska 1981, 42-66; Spera 1999, $219 \mathrm{f}$.

13 Jastrzebowska 1981, 68; ebd. 76f.

14 Vgl. Marichal 1953, 62-64; kritisch - wie auch gegenüber zahlreichen weiteren Lesungen Marichals - Ferrua in seiner Edition der Graffiti (hier ICUR V, 12935). Ein weiteres Graffito wird sowohl von Marichal 1953, 65-67 als auch von Ferrua als eine Konsulardatierung aufgefasst (ICUR V, 12959), allerdings ist aus dem Zeitraum, in dem die Triklia genutzt wurde, kein Consul bekannt, auf den sich der Name (Rufus nach Marichal; Omalus nach Ferrua) beziehen ließe. Auch die Paläographie der Graffiti erlaubt keine so präzise Eingrenzung, wie sie Marichal vornimmt (zwischen 250 und 300). 
Sicher ist einzig, dass die Triklia nach 238 angelegt und durch den Bau der basilica apostolorum in konstantinischer Zeit unzugänglich wurde. ${ }^{15}$ Einen wichtigen Anhaltspunkt für die Datierung der Graffiti liefert jedoch die Notiz des Chronographen von 354, der in der depositio martyrum für den 29. Juni den Eintrag einer Verehrung Petri in catacumbas mit dem Konsulardatum des Jahres 258 verzeichnet. ${ }^{16}$ Vermutlich verbindet sich mit diesem Datum eine Reliquientranslation oder die Einrichtung eines gemeinsamen Festes für die beiden Apostel, ${ }^{17}$ und spätestens seit dieser Zeit muss man mit Besuchern und dem Anbringen von Graffiti in der Triklia rechnen.

Über die Besucher der Triklia und die soziale Konfiguration der dort zusammenkommenden Gruppen lässt sich nur wenig sagen. Als gesichert kann gelten, dass die Triklia größeren Gruppen die Gelegenheit zur Versammlung bot. Dafür sprechen nicht nur die Geräumigkeit und Ausstattung der Anlage. ${ }^{18}$ Häufig werden in den Graffiti mehrere Personen erwähnt, und zuweilen schließen die Bitten an die Apostel mit der Bemerkung pro nobis. Zum Teil sind es Familienangehörige, seltener Freunde, die als solche genannt werden; ${ }^{19}$ in der Regel wird die soziale Beziehung der in den Graffiti erwähnten Personen jedoch nicht erkennbar. Man kann ferner aufgrund der oben erwähnten Kalendernotiz der depositio martyrum davon ausgehen, dass der Hofkomplex der Triklia für die christliche Gemeinde Roms eine wichtige Rolle spielte. ${ }^{20}$ Mehrere Graffiti signalisieren, dass die Triklia sogar möglicherweise Besucher aus italischen Städten und aus Afrika anzog. ${ }^{21}$ Insgesamt erweckt die Triklia den Eindruck einer von verschiedensten Gruppen besuchten Kultstätte, die ihren Besuchern Gelegenheit zum Vorbringen ihrer Anliegen gab.

Ergiebiger als Fragen zu den sozialen Grundlagen der Apostelverehrung in der Triklia unter S. Sebastiano, ist es, anhand der Graffiti zu bestimmen,

15 Zu den unterschiedlichen Datierungsansätzen der basilica apostolorum s. u., S. 97-101.

16 MGH AA IX, 71: III kal. Iul. Petri in Catacumbas et Pauli Ostense, Tusco et Basso cons. Das Toponym in catacumbas ist eindeutig auf den Trikliakomplex zu beziehen (vgl. Guarducci 1986, 840-842).

$17 \mathrm{Zu}$ den unterschiedlichen Hypothesen bezüglich des Ursprungs der Petrus- und Paulusverehrung an der via Appia s. u., S. 256 mit Anm. 148.

18 Die Triklia misst ca. $30 \mathrm{~m}^{2}$, war zum Hof hin mit einer Portikus abgeschlossen und an den östlichen und nördlichen Begrenzungswänden mit Sitzbänken ausgestattet (vgl. Jastrzebowska 1981, 67-69).

19 ICUR V, 12938 (avus, parentes, patruus); 13094 (coniunx, filius/-a, pater); 12930 (cum parentibus); 12923 (cum filiis et omnibus suis); 12957 (fratrem cum suis); 12942 u. 12948 (cum suis); 13092 (cum suis omnibus); 13024 (cum suis amicis).

20 Die depositio martyrum stellt mit hoher Wahrscheinlichkeit einen Auszug aus dem offiziellen Festkalender der römischen Gemeinde dar; vgl. dazu auch u., S. 257.

21 ICUR V, 12911 wird von Ferrua für eine Auflistung von Klerikern aus unterschiedlichen Städten Italiens gehalten (Marichal interpretierte das Graffito als Speisezettel!); ICUR V, 12966 erwähnt die civitas Benevent, aus der der Schreiber des Graffitos zu stammen scheint (zurückhaltend Eck 1995, 216); zu Hinweisen auf afrikanische Besucher vgl. u., Anm. 145. 
welche Erwartungen die Besucher des Komplexes mit der Kommemoration verbanden, und wie sie ihr Verhältnis zu den verehrten Heiligen bestimmten. Trotz ihrer auf den ersten Blick stereotypen Formeln erlauben die Graffiti wesentliche Einblicke in die mentalitätsgeschichtlichen Voraussetzungen, auf denen die Formen des Heiligenkults im ausgehenden 3. Jh. basierten.

\section{1. Refrigerium, pax, caritas und die Konstituierung eines grenzüberschreitenden Handlungszusammenhangs}

Erhalten geblieben sind etwa 330 Graffiti, in denen die Apostel Petrus und Paulus um ihre Fürbitte angerufen werden. ${ }^{22}$ Der Interzessionscharakter tritt in den Anrufungen klar hervor. ${ }^{23}$ In den meisten Fällen wird ein konkreter Anlass nicht genannt: Die Anrufe erschöpfen sich häufig in allgemeinen For-

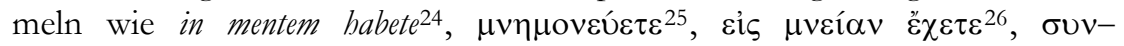
$\tau \eta \rho \eta ́ \sigma \alpha \tau \varepsilon^{27}$, petite ${ }^{28}$ und in den Namen derjenigen, denen die Aufmerksamkeit der Apostel gelten soll. Doch auch in den Fällen, in denen die Schreiber der Graffiti ihre Wünsche näher bezeichnen, sind die Ausdrücke meist doppeldeutig und lassen sich nicht auf eine konkrete Absicht beziehen. ${ }^{29}$ Allgemeine Segenswünsche wie vivere, conservare, bene navigare, salvare ${ }^{30}$ sind in raum-zeitlicher Hinsicht nur schwer verortbar: Ob sich die Bitten auf zeitliche oder jenseitige Anliegen beziehen, ist nur schwer zu entscheiden. Die Graffiti zeigen jedoch, dass man sich von den angerufenen Heiligen ${ }^{31}$ ihren Beistand

22 Vgl. ICUR V, 12907-13096; Carletti 1997, 148 unterscheidet 332 Graffiti. Die Lesung der Graffiti wird z. T. erheblich erschwert durch die Schriftform, den mitunter fragmentarischen Erhaltungszustand, Überschreibungen und die Schwierigkeit, die einzelnen Anrufungen voneinander abzugrenzen. In mehreren der im folgenden zitierten Fälle sind daher alternative Lesungen möglich; es wird die Lesart von Antonio Ferrua in seiner Edition in den ICUR zugrundegelegt.

23 Abgesehen von den Bittformeln und -inhalten erhellt dies auch aus der verschiedentlichen Eigenbezeichnung der Graffitischreiber als „Sünder“ (peccator) (vgl. ICUR V, 12941; 12967; 13028), die nicht als Eigenname aufgefasst werden kann.

24 ICUR V, 12912-12914, 12920-12922, 12936, 12954, 12957, 12964, 12973, 12976, 12978, 12980, 12992f., 12997-12999, 13000f., 13010f., 13015f., 13020, 13045, 13067, 13073, 13077, 13094.

25 Ebd. 12946, 13013, 13050, 13052, 13060.

26 Ebd. 13049, 13055f., 13082.

27 Ebd. 13061, 13071.

28 Ebd. 12918, 12931, 12933, 12937, 12966, 12970, 12989, 13009, 13096.

29 Vgl. Pietri 1983 (a), 659.

30 ICUR V, 12948, 13094 (vivere); 12991, 12996, 13026 (conservare); 12973 (navigare); ähnlich unbestimmt 12976 (salvetis). Zur Bedeutung von navigare, das sich keineswegs auf eine konkrete Seereise beziehen muss, vgl. die Bemerkungen von Ferrua zu ICUR V, 12959.

31 Petrus und Paulus werden in den Graffti sowohl als Apostel (ICUR V, 13065) als auch als Märtyrer (ebd., 12955) bezeichnet. 
sowohl im Jenseits und beim Jüngsten Gericht ${ }^{32}$ als auch schon im gegenwärtigen Leben erhoffte; letzteres kommt am deutlichsten in der Bitte, dass man noch viele Jahre leben möge, zum Ausdruck. ${ }^{33}$ Insgesamt wird man festhalten müssen, dass der unbestimmte Bezugsrahmen zwischen Zeitlichkeit und Eschatologie, Diesseitsorten und Jenseitstopographie ein Charakteristikum der Graffiti ist. Dieser Umstand, dass die Welten der Lebenden und der Toten keine klar voneinander getrennten Ebenen bilden, sollte weniger dazu Anlass geben, die Äußerungen eindeutig einem zeitlichen und räumlichen Kontext zuweisen zu wollen. Wie im folgenden mit Blick auf den in den Graffiti und den Grabinschriften häufig erscheinenden Begriff des refrigerium gezeigt werden soll, eröffnet gerade die in der Terminologie angelegte Verbindung beider Welten Einsichten in das Verhältnis der Kommemorierenden zu den Verstorbenen insgesamt und zu den Heiligen als den „besonderen Toten".

In den Graffiti unter S. Sebastiano ist mehrfach von refrigerium bzw. refrigerare die Rede. Mit refrigerium wird zum einen der Jenseitsort oder -zustand bezeichnet, in dem sich die Heiligen befinden, und an den die Seelen der Verstorbenen durch die Fürsprache der Heiligen geführt werden sollen. ${ }^{34}$ In

32 Für Bitten in eschatologischen Anliegen vgl. ICUR V, 12970: [Pe]tre e[t Paule pe]tite pro ... quinta, [u]t possimu[s a]d vos venir [e] (ähnlich 13077). Als Bitten für bereits Verstorbene sind zu verstehen 12954: in mente habetote spirita sancta; 12975: Petre et Paule sancta spirita vestra ad se addugant et in aeterno refrigerio (zu den spirita sancta als Bezeichnung für die abgeschiedenen Seelen vgl. Delehaye 1927, 30-32, Pietri 1991, 18f.); in denselben Zusammenhang gehört auch das commendare in $13070 \mathrm{u}$. 13045. Der Wunsch in pace/in deo vivas (ebd. 13031, z. T. stark fragmentarisch; vgl. auch 13048; 13094 [vivere]; 13033; 13092 [in pace]), der sich auch in Grabinschriften derselben Zeit als Segenswunsch für die Toten findet, muss nicht auf einen eschatologischen Kontext verweisen (vgl. u., S. 52-54). Ferrua 1965 sieht zwar insgesamt einen stärker jenseitsorientierten Charakter der Bitten, hebt jedoch ebenfalls die enge Verbindung zwischen Interzession in jenseitigen und diesseitigen Anliegen hervor.

33 ICUR V, 13071.

34 Unter S. Sebastiano wird dieser Wunsch explizit geäußert in ICUR V, 12975: [Petre] et Paule sa[ncta spiri] ta vestra a[d se add] ugant et in [aeter] no refriger [io]; als Jenseitsort erscheint refrigerium offensichtlich auch im Graffito 12993: Petre et Paule in mente abete [Ur] sinum in r[ef]rigerium. Der von Stuiber 1957 unternommene Versuch, den Begriff refrigerium in den Grabinschriften konsequent auf einen unterirdischen Zwischenzustand zu beziehen, in dem sich die Toten vor der Auferstehung am Jüngsten Tag befinden, kann nicht überzeugen. Zwar ist die Vorstellung von einem Wartezustand in der spätjüdischen und frühchristlichen Literatur nachweisbar (vgl. Stuiber 1957, 17-105), und Tertullian bezeichnet diesen Zustand als ein refrigerium interim. Gleichzeitig dient refrigerium jedoch auch dazu, den Jenseitszustand der Märtyrer, die sich im Unterschied zu den normalen Toten bereits direkt nach dem Tod bei Gott befanden, zu bezeichnen (vgl. oben ICUR V, 12975: aeternum refrigerium; auch Tertullian kennt neben dem refrigerium interim ein aeternum refrigerium: Tert., anim. 33, 11; ders., apol. 49, 2). Offenkundig bilden interim bzw. aeternum modifizierende Adjektive für den Begriff des refrigerium, der für sich allein genommen und in seiner Grundbedeutung nichts anderes bedeutete als einen glücklichen Jenseitszustand (so auch Finé 1958, 181). Es besteht dementsprechend kein Anlass zu der Annahme, dass refrigerium in den Sepulkralinschriften über diese Grundbedeutung hinausgehend eine Verengung auf das refrigerium interim impliziert. In diesem Zusammenhang ist ferner zu berücksichtigen, dass differenzierte 
dieser Bedeutung als Zustand der Toten erscheint der Ausdruck auch schon in den frühen christlichen Grabinschriften Roms, die noch dem 3. Jh. angehören. ${ }^{35}$ Zum anderen bezeichnet der Begriff bestimmte vota, die den Aposteln Petrus und Paulus von den Besuchern des Hofkomplexes dargebracht wurden. ${ }^{36}$ Die Polemik zahlreicher Bischöfe des ausgehenden 4. Jh. gegen Mahlfeiern an den Märtyrergräbern ${ }^{37}$ sowie die räumliche Disposition der Triklia, die den zeitgenössischen Totenkultanlagen zur Abhaltung von Mahlfeiern entspricht, lassen an der Deutung dieser vota keinen Zweifel: Es handelte sich um Mähler, die von den Besuchern in der Triklia abgehalten wurden. Auch diese Mahlfeiern zum Gedenken der Märtyrer haben ihr Pendant in christlichen Kommemorationsfeiern für „,normale“ Verstorbene. Archäologische Zeugnisse und Inschriften in den römischen Begräbnisstätten erweisen eindeutig, dass bereits in vorkonstantinischer Zeit Mähler eine verbreitete Praxis der christlichen Totenkommemoration gewesen sein müssen. ${ }^{38}$

In welchem Verhältnis stehen diese beiden Bedeutungen von refrigerium zueinander? Trotz der terminologischen Übereinstimmung sieht die Forschung hierin traditionell zwei unterschiedliche Dinge, die durch denselben Begriff ausgedrückt worden seien. ${ }^{39}$ Die Mahlfeier stehe der Grundbedeutung von refrigerium/refrigerare (Abkühlung mit Wasser; Erquickung durch Trank und Speise) nahe und stelle eine direkte Fortsetzung paganer Totenkultprak-

theologische Konzepte wie der Zwischenzustand nicht unbedingt auf breiter Basis rezipiert wurden: Gerade Tod und Nachleben geben Anlass zu unterschiedlichen und z. T. widersprüchlichen Haltungen, bei denen sich theologische Deutungen nicht einfach in eine allgemeine Mentalität übersetzen lassen (vgl. dazu die Einwände von Sanders 1991 [1976], 149; Pietri 1980; Février 1984, 164).

35 Zu berücksichtigen ist, dass sich in Rom keine christlichen Inschriften vor dem 3. Jh. nachweisen lassen. Spezifische Formulare, die Hinweise auf die religiöse Orientierung der Bestatteten enthalten, begannen sich erst während des 3. Jh. ansatzweise auszubilden und erlauben zudem in dieser frühen Entwicklungsstufe keine sichere Zuweisung einer Inschrift als christlich (vgl. Mazzoleni 1998, 153f.). Da sich die frühen christlichen Inschriften in ihrem Formular von den paganen meist nicht unterscheiden, ist es daher der Fundkontext, der über die Einstufung einer Inschrift als christlich entscheidet (zum methodischen Prinzip vgl. Carletti 1988, 115-118; ders. 1997, 143). Die frühesten datierten christlichen Inschriften stammen aus dem Beginn der zweiten Hälfte des 3. Jh. (vgl. die Übersicht bei Ferrua 1978, 584-597).

36 ICUR V, 12981: Petro et Paulo Tomius Coelius refrigerium feci. Für die Bezeichnung des Refrigeriums als votum vgl. 12932: Dalmatius botum, is promisit refrigerium (vgl. auch 12907, dort ist refrigerium allerdings ergänzt); 13091: Eulogius votum f[ecit]; fragmentarisch erscheint votum in 12988, 13044. Der Charakter des Refrigeriums als einer Gabe an die Apostel wird ebenfalls deutlich in 12994: Petro et Pau]lo refrige[ravit] (oder: refrige[rium fecit]) Ursinus; 13003: at Paulu[m] et Pet [rum] refri[geravi]. Für refrigerare als Handlung ohne direkten Bezug auf die Apostel vgl. 12942: idus nov $<e>n b[$ res] refrigerav[it F]elicissimus cum s[uis]; 12974: idus [Iuli]as refrigeravit Restituta [Pr]imitivus; 12961: XIIII kal Apriles refrigeravi Parthenius in deo. Auf den Jenseitszustand zu beziehen ist refrigerium in 12975 und 12993.

$37 \quad$ Vgl. dazu u., S. 168, Anm. 331.

38 Vgl. die umfassende Dokumentation von Février 1978.

39 Stuiber 1957, 114; Schneider 1928, 22; Rotach 1994, 36. 
tiken dar. Für den Jenseitszustand hingegen sei refrigerare in einer übertragenen und zugleich umfassenderen Bedeutung (Ruhe/Erholung/Tröstung) charakteristisch. Derartige Assoziationen seien von Tertullian mit der Bezeichnung refrigerium belegt worden, und bald darauf habe sich refrigerium im lateinischen christlichen Sprachgebrauch zu einem terminus technicus für einen glückseligen Jenseitszustand entwickelt. ${ }^{40}$

An diesem Bild erscheinen jedoch Modifikationen angebracht. Es ist richtig, dass die Bezeichnung refrigerium für den christlichen Jenseitszustand nicht aus bestimmten paganen Totenkultpraktiken und damit verbundenen Jenseitsvorstellungen einer Abkühlung des Toten durch Wasser abgeleitet werden kann. Dagegen spricht zum einen, dass der Begriff refrigerare in paganen Inschriften nur selten nachweisbar ist und seine Verwendung offenbar wesentlich auf einen christlichen Sprachgebrauch zurückgeht. ${ }^{41}$ Zum anderen lassen sich, lange bevor refrigerare in den Grabinschriften erscheint, Jenseitsvorstellungen nachweisen, die sich unbeeinflusst von Totenkultpraktiken entwickelt haben und dann seit Tertullian als refrigerium bezeichnet wurden: Der lateinische Begriff artikulierte also eine bereits bestehende Vorstellung, aber diese Vorstellung ist nicht durch den Begriff hervorgerufen worden.

Das bedeutet jedoch nicht, dass die beiden Verwendungsweisen von refrigerium - Mahlfeier und Jenseitszustand - ein paralleles Eigenleben ohne wechselseitige Beeinflussung geführt hätten. Bereits die Tatsache, dass refrigerium in den Graffiti unter S. Sebastiano in beiden Bedeutungsvarianten verwendet wurde, deutet auf eine enge Verbindung hin. Eine rein eschatologische Interpretation des Refrigeriums, in dem sich nach Ausweis der Graffiti und Se-

40 Tert., monog. 10, 4 über das eucharistische Opfer einer Witwe am jährlichen Todestag ihres verstorbenen Mannes: enimvero pro anima eius orat et refrigerium interim adpostulat ei et in prima resurrectione consortium, et offert annuis diebus dormitionis eius. Eine ausführliche Diskussion dieser und weiterer Belege bietet Stuiber 1957, 17-105; zur Entwicklung der Terminologie Finé 1958, 150-196, nach dessen Auffassung Tertullian den Begriff refrigerium im lateinischen Sprachgebrauch prägte; bei Cyprian habe er sich bereits zu einem terminus technicus entwickelt. Die Vorstellung ist älter als der lateinische Begriff, der sie bezeichnet; vgl. Iren., haer. 3, 16, 4 (Simeon...infantem, quem in manibus portabat...ipsum confitens esse Christum filium Dei, lumen hominum et gloriam ipsius Israel et pacem et

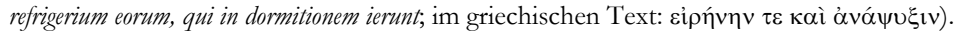

41 Die üblichen Bezeichnungen, die sich in Stiftungsinschriften für Mahlfeiern im Zusammenhang mit dem Totenkult finden, sind epulum, cena, crustulum et mulsum (seltener epulatio, epulae, visceratio, prandium (vgl. das bei Laum 1914, Bd. 2, 161-197; Duncan-Jones 1982, 171-184, 188-198, 201 206; Mrozek 1987, 37-46 zusammengestellte Material). Neben der großen Zahl frühchristlicher Belege sind $\mathrm{m}$. W. nur vier Inschriften bekannt, die refrigerium als Mahlfeiern anlässlich des Totengedenkens in einem vermutlich paganen Kontext erwähnen; bei sämtlichen handelt es sich um späte Zeugnisse: Drei der genannten Inschriften lassen sich in das 4. Jh. datieren (CIL XI, 6222; eine Stiftungsinschrift aus Feltria [vgl. Mrozek 1978, 359-362]; CIL VIII, 20780); bei der vierten, undatierten Inschrift erscheint das refrigerare erst in einem späteren Zusatz (CIL XIV, 3323). Mohrmann 1961, 82, Anm. 3 interpretiert refrigerium als eine vulgärlateinische Form, die sich erst durch den christlichen Sprachgebrauch allgemein eingebürgert habe; ebenso Janssen 1938, 237. 
pulkralinschriften die Apostel und andere Tote befanden, als eines entrückten, der Welt der Lebenden enthobenen Jenseitszustands greift offensichtlich zu kurz. ${ }^{42}$ Vielmehr stehen die Refrigerien an den Gräbern der Toten und der Zustand, in dem sich die Toten befanden, in einem engen inneren Zusammenhang. Einen klaren Hinweis darauf liefern die Aufschriften auf Goldgläsern, von denen zahlreiche Exemplare in den Mörtel von Katakombengräbern eingelassen wurden. Trotz dieses Fundkontextes hatten diese Gläser ursprünglich keine sepulkrale Funktion, sondern waren glückbringende Geschenke, die zu Lebzeiten überreicht und dem Empfänger auch nach dem Tod als eine Art Apotropaion mit ins Grab gegeben wurden. ${ }^{43}$ Auffällig ist, dass auf den christlichen Goldgläsern die traditionellen Glückwünsche und Anreden (wie pie, zeses [trink und lebe!] vivas/vivatis; dulcis anima) ${ }^{44}$ durch diesel-

42 Zur Bedeutung von refrigerium als einem Ruhezustand der Toten vgl. Tert., test. anim. 4: ossibus et cineribus eius refrigerium comprecaris et ut bene requiescat apud inferos cupis; vgl. dens., monog. 10. Wichtig ist jedoch, dass das refrigerium der Toten nicht eine empfindungslose Ruhe, sondern immer auch eine Erquickung oder Tröstung bedeutete (vgl. dazu Dassmann, in: Colpe 1996, 357), wodurch die Verbindung mit dem refrigerium der Lebenden und den darin zutage tretenden Handlungsbeziehungen möglich wurde. Ähnliches gilt für den Begriff der pax, der in frühen Grabinschriften mit dem refrigerium verbunden wurde (vgl. u., S. 52-54).

43 Entsprechendes gilt für Münzen und Medaillons, die sich ebenfalls in großer Zahl in den Wandgräbern der Katakomben erhalten haben. Mittag 1999, 206-214 plädiert überzeugend für eine apotropäische Deutung dieser Medaillons und verweist darauf, dass sie schon zu Lebzeiten als augurale Geschenke überreicht wurden. Zur sozialen Bedeutung und Verbreitung dieser Geschenkpraktiken im spätantiken Rom vgl. A. Alföldi/E. Alföldi 1990, 12-19. Auch die Goldgläser sind in diesen Kontext einzuordnen: Da auf manchen Goldgläsern Hochzeitsszenen abgebildet sind (vgl. Morey 1959, 72; Tafel XXXVI, Abb. 447 mit der Aufschrift vivatis in deo), ist anzunehmen, dass derartige Gläser häufig als Hochzeitsgeschenke versandt wurden; ferner dürften sie als Geschenke an Geburtstagen, Jahreskalenden und Märtyrerfesten gedient haben (so auch Vopel 1899, 84f., 93). Eine unmittelbare Parallele zu den Goldgläsern und den Münzen stellen ferner die Abdrücke von Siegelringen der Verstorbenen auf dem frischen Mörtel der Gräber dar: Auch diese Ringe enthielten neben dem Namen des Besitzers augurale Akklamationen (u. a. vivas/zeses; vgl. Ferrua 1986, 112f.). De Santis 1994, 47f. u. Felle u. a 1994, 154f. interpretieren die Gläser als Ausdruck einer symbolischen Mahlgemeinschaft mit dem Toten; für eine primär dekorative Funktion plädiert Bisconti 1998, 80. Diese Funktionen müssen sich nicht gegenseitig ausschließen; für den hier interessierenden Zusammenhang ist vor allem die Christianisierung des Inschriftenformulars von Interesse.

44 Vgl. Morey 1959: pie zeses: nr. 2, 14, 23, 29, 39, 41, 44, 47-49, 78, 89-92, 96, 99, 113, 114, 193, 205, 223, 235, 236, 239, 241 (vivas, pie), 244, 259, 261, 266, 273, 300, 302, 314, 344, 346, 366, 391, 418, 420, 426, 441, 446, 451; vivas/vivatis/vive/zeses: 9, 10, 12, 13, 15, 17, 19, 24, 30, 37, 40, 45, 50, 58, 59, 71, 75, 93f., 109f., 187, 204, 209, 224, 227, 233, 289f., 299, 301, 308-309, 310f., 315f., 336, 343, 377, 397, 399, 400, 407, 411, 419, 448, 458; anima dulcis: nr. 3, 15, 18, 20, 26, 115. S. ferner Dessau 8610, CIL XV, 7050, 7052f. (anima dulcis); Dessau 8611 (Antonia dulcis), 8612 (anima felix, vivas). Für eine Verbindung von anima dulcis mit vivas und/oder pie zeses vgl. Morey, nr. 48, 90, 109, 310, 426. Zahlreiche dieser Gläser tragen eindeutig christliche Motive (alt- und neutestamentliche Szenen, Christusmonogramme, Christus, Heilige); der „Gute Hirte“ kann hingegen nicht als eindeutig christliches Symbol gelten. Für diese Gläser mit christlichen Bildmotiven vgl. Morey 1959, nr. 29, 44, 47-49, 78, 223, 235, 241, 314, 344, 366, 420 (pie zeses); nr. 37, 50, 58, 71, 75, 187, 224, 397, 448 (vivas u. ä.); 109, 310 (anima dulcis, vivas). In vielen Fällen lässt sich nicht entscheiden, ob der Auftraggeber eines Glases Christ war oder nicht. 
ben Zusätze ergänzt wurden, die sich in derselben Zeit auch in der christlichen Sepulkralepigraphik finden: in pace, in pace Dei, in Deo; in einem Fall taucht dabei auch das Wort refrigerare auf. ${ }^{45}$ Wie für die Toten, die sich nach dem Wortlaut zahlreicher Grabinschriften in pace oder in Deo befanden, galt auch für die Lebenden, dass sie in pace oder in Deo trinken und leben mochten. Dass diese Gläser möglicherweise bei den im Gedenken an die Toten gefeierten Refrigerienmählern zum Einsatz kamen, ${ }^{46}$ macht die Beziehung zwischen diesen beiden Welten noch enger.

Trotz ihrer Anklänge an Formulierungen der Grabinschriften besteht kein Grund zu der Annahme, dass sich die Formulare auf den Goldgläsern aus der Funeralepigraphik entwickelt hätten. Vielmehr gehen beide Formulare auf eine einheitliche Grundvorstellung zurück: Das Mahl im Leben und der Jenseitszustand im Tod standen unter denselben auguralen Leitbegriffen, die die gesamte Existenz, diesseits und jenseits des Grabs, überspannten und die Wünsche für die Toten wie für die Lebenden in gleicher Weise prägten. Diese Hypothese wird noch durch weitere Beobachtungen gestützt. Zwar ist es in zahlreichen Refrigeriuminschriften Gott, der dem Toten das refrigerium gewähren soll (deus refrigeret spiritum tuum). ${ }^{47}$ Daneben erscheinen jedoch auch Akklamationen, die dem Toten von seiten der Lebenden das refrigerium anwünschen.

45 Vgl. Morey 1959, nr. 220 (in pace), 228 (semper im (!) pace gaudeas), 285, 388 (vivas/vivatis in pace dei); 292 (anima dulcis, pie zeses in deo), 312 (bilaris cum tu(is) pie zeses in deo), 42 (viv)as in deu(m), 447 (vivatis in deo), 460 (vivas in Cr(isto); nr. 36 (bilaris vivas cum tuis feliciter, semper refrigeris im (!) pace dei); z. T. kombiniert mit Szenen des Alten und Neuen Testaments oder mit christlichen Symbolen (285, 388, 292, 312, 36). Zur starken Verbreitung der Formel in pace in der frühchristlichen Epigraphik vgl. Carletti 1988, dens. 1997.

46 Vgl. Février 1984, 166 u. 172, der allerdings auch die Produktion der Goldgläser mit der Totenmahlpraxis in direkte Beziehung setzt und meint, die Gläser seien eigens für Totenmähler gefertigt worden (vgl. auch dens. 1991, 58, wo er die Akklamation pie, zeeses auf den Goldgläsern als Einladung zum Totenmahl interpretiert). Zu einer derartigen Vermutung besteht jedoch keine Veranlassung, vgl. o., Anm. 43.

47 Als Beispiele aus dem 3. Jh. sind zu nennen: ICUR VIII, 21694: Baia [n]a, dulc [is] anima, refrigeret deus spiritum tuum (Coemeterium maius; in das 3. Jh. gesetzt von Carletti 1997, 146); ICUR X, 26369: dom(inus) refr(igeret) spir(itum) tuum (untere Ebene der Pamphiluskatakombe; von Josi im Jahr 1924 in die 1. Hälfte des 3. Jh. datiert; dies ist allerdings zu hoch gegriffen, da sich die Inschrift am Ende des langen Hauptgangs in Verlängerung der Zugangstreppe befindet, also nicht in die früheste Phase der unteren Ebene fällt, deren Anlage im übrigen wohl erst in der zweiten Hälfte des 3. Jh. begonnen wurde, vgl. Fiocchi Nicolai 1998, 30); ICUR X, 26781: deus te refrigeret (coemeterium Bassillae „ad Hermetem“; das Ankersymbol legt eine frühe Datierung nahe; vgl. Mazzoleni 1998, 152). Das Formular dieses Inschriftentyps, in dem Gott dem Toten ein Refrigerium gewährt, indiziert allerdings nicht per se ein hohes Alter: Einige der von Carletti 1976, 61 als ,piu antiche iscrizioni romane" bezeichneten Refrigeriuminschriften sind mit Sicherheit erst nachkonstantinisch (z. B. ICUR IX, 24926 [Christusmonogramm] u. 24969 (südlicher Bereich der sogenannten „regione del battistero“ des Priscillacoemeteriums [ $\mathrm{b}^{\mathrm{I}} 13$ nach Tolotti 1970, tav. 1; die Inschrift wurde dort allerdings nicht in situ gefunden], der von Tolotti 1970, 347 erst ins fortgeschrittene 4. Jh. datiert wird), ICUR II, 6152 (Commodillacoemeterium, Gang Bb, ein retro sanctos, das wie das gesamte Coemeterium erst aus der 2. Hälfte des 4. Jh. datiert, vgl. Carletti 1994, $5-8)$. 
In diesen Fällen ist es naheliegend, dass das refrigerare des Toten und die ebenfalls als refrigerium bezeichnete - Mahlfeier, die die Kommemorierenden abhielten, in einen engen Bedeutungszusammenhang gebracht wurden. Der Zuruf pie, zeses, den die Lebenden bei Mählern aneinander richteten, findet sich als Graffito mehrfach an christlichen Gräbern, ${ }^{48}$ und in Akklamationen wie Ianuaria, bene refrigera et roga pro nos (!) ${ }^{49}$ ist nicht sicher zu entscheiden, ob der Schreiber beim refrigerium der Ianuaria eher einen Jenseitszustand oder eine Mahlfeier vor Augen hatte, die zum Gedächtnis an die Tote gehalten wurde. Die Vorstellung vom refrigerium, in dem sich der Tote nach Ausweis der Graffiti und Sepulkralinschriften befand, scheint wesentlich beeinflusst gewesen zu sein vom Akt der Mahlfeier, den die Lebenden in der Erinnerung an den Toten vollzogen. ${ }^{50}$ Vor diesem Hintergrund stellt sich die Frage, ob es wirklich sinnvoll ist, zwischen dem refrigerium als Jenseitszustand und dem Totenmahl zu unterscheiden, oder ob die semantischen Übereinstimmungen nicht eher als Hinweis auf eine spezifische Konzeptualisierung des Verhältnisses der Lebenden zu den Toten zu deuten sind, in der eine klare Grenze zwischen diesseitigem und jenseitigem refrigerium nicht gegeben war. ${ }^{51}$

In letztere Richtung weist auch die passio Perpetuae et Felicitatis, der für die Frage, was mit den refrigeria in Inschriften und Graffiti gemeint ist, insofern

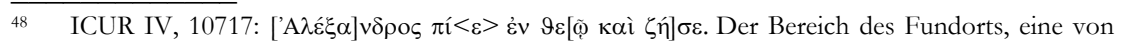
der area I des Kallixtcoemeteriums abzweigende Galerie (S), wird von Spera 1999, 125 ins fortgeschrittene 3. Jh. datiert (zum Fundort vgl. de Rossi 1864-1877, Bd. 2, 271f. und ebd., 102*). Pie, zeses findet sich auch unter den Graffiti von S. Sebastiano (ICUR V, 12909), dort offensichtlich ebenso als Aufforderung an die Märtyrer gerichtet wie die gleichlautende Akklamation auf einer Märtyrermensa in Nordafrika (Altava/Mauretania Caesarea): Hier schließt sich an die Inschrift

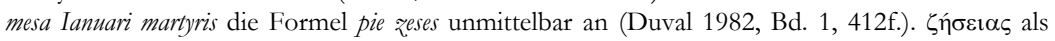
alltäglicher Trinkspruch bei Symposien ist belegt bei Cass. Dio 72 (73), 18, 2; in dieselbe Richtung weist das häufige Vorkommen der Formel auf den Goldgläsern, die als Trinkgefäße fungierten.

49 ICUR IV, 9913 (Kallixtcoemeterium in einem südlich an die area I südlich anschließenden Bereich [de Rossi 1864-1877, Bd. 3, 353]; diese Erweiterung ist vermutlich nicht lange nach der Anlage der area I, also noch im 3. Jh. entstanden: Darauf weisen die hohe Anzahl griechischer Inschriften, das lakonische Inschriftenformular, der Anker als Symbol hin [vgl. ebd., Bd. 2, 254257, Bd. 3, 349-354]). Vgl. ähnlich ICUR V, 13886: Cervonia Silvana refrigera cum spirita sancta (datiert in das Jahr 291); Murelius Ia [nuarius] care, refriger[a (untere Ebene des Priscillacoemeteriums, im Bereich von O22; vgl. de Rossi 1884-1885, 61. Zum Alter der unteren Ebene s. Tolotti 1970, 336-340: Sie wurde in derselben Zeit angelegt wie die Randbereiche des ältesten Kerns in der ersten Ebene, vermutlich seit dem Ende des 3. Jh.).

50 Die materialistisch-realistische Auffassung des jenseitigen Refrigeriums als „Erfrischung“ wird hervorgehoben von Ferrua 1938, 160; Mohrmann 1961, 87-90. In diese Richtung weist auch,

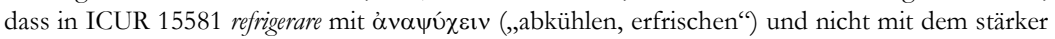

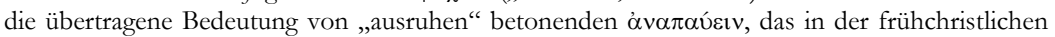
Literatur ebenfalls als eine mögliche Übersetzung von refrigerare erscheint (vgl. Schneider 1928, 9), wiedergegeben wird. Auch hierin liegt ein Hinweis, dass die Vorstellung vom Refrigerium, in dem der Tote sich befand, stark von der Anschauung der Mahlpraxis, die an seinem Grab stattfand, geprägt war.

51 Zu den Abgrenzungsschwierigkeiten vgl. auch Ferrua 1941, 460f., Stuiber 1957, $115 f$. 
ein hoher Quellenwert zukommt, als die Berichte von Perpetua und Saturus, die der Verfasser der passio verarbeitet hat, sprachgeschichtlich typische Beispiele für die lateinische Umgangssprache des frühen 3. Jh. in Nordafrika darstellen und damit dem Idiom der Besucher, die ihre Graffiti in der Triklia in Rom hinterließen, sehr nahe kommen dürfte. ${ }^{52}$ In der passio taucht der Begriff refrigerare mehrfach auf. Für den gegenwärtigen Zusammenhang interessiert vor allem die Vision des Saturus: Nach seinem Martyrium sieht sich Saturus, wie er zusammen mit Perpetua von vier Engeln an einen Ort des Lichts mit einem Garten und einem Tor entrückt wird, an dem sie auch weitere Märtyrer treffen. Doch bleiben die Heiligen nicht in ihrem entrückten, weltenthobenen Erlösungszustand: Zwei Kleriker, Bischof Optatus von Karthago und einer seiner Presbyter, die im Streit miteinander liegen, bitten die Märtyrer um ihre Vermittlung. Perpetua und Saturus gehen darauf ein und ziehen sich mit den beiden Klerikern in einen Teil des Gartens zurück. Schließlich ermahnen die Engel den Bischof und seinen Presbyter, sie mögen Perpetua und Saturus „refrigerieren“ lassen (sinite illos refrigerent) und ihre Streitigkeiten untereinander beilegen; die Kleriker müssen die Märtyrer daraufhin verlassen, und das Tor beginnt sich hinter den Märtyrern zu schließen, die sich dort unter einer Menge von Brüdern wiederfinden. ${ }^{53}$

In offenkundiger Weise verschränken sich in der Vision des Saturus unterschiedliche zeitliche und räumliche Ebenen. Der Konflikt der streitenden Kleriker, die sich von den Märtyrern eine schiedliche Beilegung ihrer Auseinandersetzung erhoffen, hat seinen Ort im Diesseits der nordafrikanischen Gemeinde von Karthago, und den Märtyrern fällt in der Vision des Saturus dieselbe Rolle der friedensstiftenden Versöhner zu, die sie ein halbes Jahrhundert später während der decischen und valerianischen Verfolgungen bei der Ausstellung von Friedensbriefen an die lapsi beanspruchten. In dem Tor, das sich vor Optatus und seinem Presbyter schließt und die Märtyrer mit vielen Brüdern und Märtyrern zurücklässt, sind möglicherweise Assoziationen mit dem Gefängnis, in dem Perpetua und ihre Gefährten saßen und häufig die Besuche der Brüder empfingen, enthalten. ${ }^{54}$ Deutlich scheint in jedem Fall, dass refrigerare nicht allein den paradiesischen Erlösungszustand benennt, in den Perpetua und Saturus nach ihrem Martyrium versetzt zu werden hofften: Das refrigerium, in dem sich die Märtyrer nach ihrer Vollendung befinden,

\footnotetext{
52 Zur Stilistik der in der passio Perpetuae erhaltenen Aufzeichnungen von Perpetua und Saturus und zu Hinweisen auf die Präsenz afrikanischer Besucher in der Triklia s. u., S. $73 f$.

53 Pass. Perp. 11-13.

54 Vgl. Bremmer 2000, 109 für eine vergleichbare Assoziation zwischen dem Gefängnis und dem Strafort des Dinocrates in Perpetuas Dinocratesvision. Tertullians ausdrückliche Versicherung, Perpetua habe in ihrer Jenseitsvision nur Märtyrer gesehen (Tert., anim. 55, 4: Perpetua, fortissima martyr, sub die passionis in revelatione paradisi solos illic martyras vidit), blendet ein ganz wesentliches Element der Passio Perpetuae aus, nämlich die Gegenwart der vielen Brüder und damit die Beziehung zwischen diesseitigen Vergemeinschaftungsformen und der Jenseitsvision.
} 
steht vielmehr in enger Verbindung zu Handlungs- und Erfahrungssituationen, die im Diesseits vermittelt wurden - durch Mahlfeiern, die ebenfalls die Bezeichnung refrigeria trugen: So berichtet die passio Perpetuae mehrfach davon, dass die christlichen Glaubensgenossen Perpetua und ihre Gefährten im Gefängnis aufgesucht und einander dort ein wechselseitiges refrigerare hätten zuteil werden lassen. ${ }^{55}$

Aus dem Bisherigen ist deutlich geworden, dass die Vorstellungen vom Jenseitszustand offenbar stark von den Praktiken der Mahlfeiern beeinflusst waren, die die Lebenden im Gedenken an die Toten vollzogen. Eine nähere Untersuchung verdeutlicht, dass diese als refrigerium bezeichneten Mahlfeiern in einem weiteren Kontext christlicher Gemeinschaftsbildung standen: refrigerare und verwandte Ausdrücke der christlichen Sepulkralepigraphik bezeichneten Handlungsbeziehungen und Haltungen, die für die Identitätsstiftung der christlichen Gemeinden von zentraler Bedeutung waren. So ist refrigerare ein Begriff, der nicht nur im Zusammenhang mit dem christlichen Totenkult erscheint, sondern zugleich starke sozialethische Implikationen beinhaltete. Er ist bei Tertullian und in den apokryphen Petrusakten (Ende des 2. Jh.) mehrfach in der Bedeutung von „Arme/Witwen/Fremde speisen“ überliefert. ${ }^{56}$ Manche Forscher haben deswegen sogar erwogen, die Refrigerien unter S. Sebastiano als regelrechte Armenspeisungen zu interpretieren, ${ }^{57}$ was aber insofern ausscheidet, als die refrigeria in den Graffiti als vota für die Apostel bezeichnet werden und sich - wie die Mahlgabe für die Verstorbenen - direkt an die Apostel wandten. Festzuhalten ist jedoch, dass mit der Bedeutung als Armen-, Fremden- und Witwenspeisung refrigerare zugleich einen wichtigen Bereich der Gemeinschaftsstiftung und Kommunikation innerhalb der frühchristlichen Gemeinden berührt.

Dies gilt nicht nur für refrigerare/refrigerium, sondern auch für andere Begriffe der Sepulkralepigraphik, die gleichzeitig eine augurale Bedeutung für das Diesseits haben und in der sozialen Organisation der christlichen Gemeinden eine zentrale Rolle spielen und deren Deutung in Grabinschriften zu kurz greift, wenn man sie ausschließlich auf den Jenseitszustand des Toten bezieht.

$55 \quad$ Vgl. u., S. 67f.

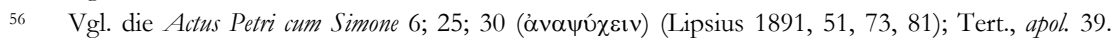
Refrigerare hat in dieser Bedeutung als karitative Speisung von Bedürftigen unbestreitbar sozialethische Implikationen, ohne allerdings ein terminus technicus für soziale Fürsorge und Armenunterstützung zu sein (vgl. Janssen 1938, 238f. zu Tertullian, ähnlich Pétré 1948, 270). Zu diesem

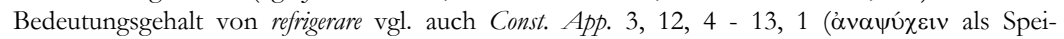
sung/Unterhalt von Witwen).

57 So Grossi-Gondi 1915, 224f.; Reicke 1951, 118 (Armenspeisung mit jüdischem Hintergrund); Hamman 1968, 211. Janssen 1938, 236, Anm. 6 äußert sich zunächst ähnlich, urteilt jedoch wenig später (ebd., 240) zurückhaltender. Der früheste explizite Beleg für eine Einbeziehung von Armen in Refrigerien für die Märtyrer ist die konstantinische oratio ad sanctorum coetum (Const., or. s. c. 12). 
Dies betrifft vor allem die pax, der in den frühesten christlichen Sepulkralinschriften Roms, die etwa derselben Zeit entstammen wie die refrigeriumGraffiti unter S. Sebastiano, eine absolute Schlüsselstellung zukommt. ${ }^{58}$ Ähnlich wie refrigerium/refrigerare erscheint in den frühen christlichen Grabinschriften pax entweder als ein an den Toten gerichteter Zuruf (pax tibi) tecum,

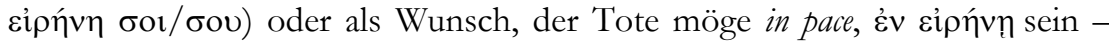
analog zu refrigera/ refrigeres oder in refrigerio.

Der Begriff pax ist zweifelsohne äußerst komplex; sein Inhalt lässt sich nur durch den jeweiligen Kontext genauer bestimmen und wird zudem seit dem 5. Jh. durch die zunehmende Stereotypie der Formel in pace immer unschärfer. ${ }^{59}$ Ähnlich wie beim refrigerium erscheint es jedoch verkürzend, diesen Frieden ausschließlich in seinen eschatologischen Dimensionen, als einen auf die Grabesruhe des Toten oder den Frieden seiner Seele im Jenseits bezogenen Begriff zu interpretieren, ${ }^{60}$ ohne seine Signalwirkung für die diesseitige Sozialordnung zu berücksichtigen. Obwohl transzendente Implikationen unbestreitbar gegeben sind, ${ }^{61}$ ist pax ein Begriff, der im Zentrum der christlichen Gemeinschaftsstiftung auch im diesseitigen Leben stand. Die pax war dabei nicht nur eine göttliche Gabe, die den Bestand der Gemeinde sicherte, sondern wurde in elementarer Weise bedingt durch das menschliche Handeln, das die Einheit und Ordnung der Gemeinde konstituierte. Der Friedensgruß pax tecum, der offenbar direkt von den oben genannten Grabinschriften aufgenommen wurde, ${ }^{62}$ das osculum pacis zu Beginn der eucharistischen Feier, das

58 Vgl. Carletti 1988, 120-122; dens. 1997, 146. Verzerrend ist die Beobachtung von Rutgers 1995,

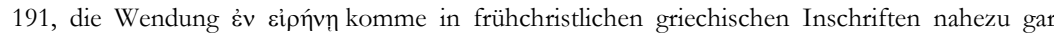
nicht vor (1\%) und spiele entsprechend in der christlichen Epigraphik - im Gegensatz zur jüdischen - keine bestimmende Rolle. Zum einen machen die griechischen Inschriften nur knapp 11 $\%$ (vgl. Carletti 1997, 143) der in den ICUR edierten Inschriften aus, die Rutgers seiner Statistik zugrundelegt (ebd. 182f.) - die Einbeziehung der bedeutungsäquivalenten lateinischen in pace-Inschriften würde Rutgers Bild stark ändern. Zum anderen betrachtet Rutgers alle in den ICUR erfassten Inschriften unterschiedslos als „,early Christian inscriptions“, ohne diesen Bestand weiter

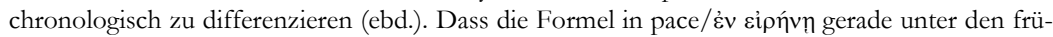
hen christlichen Inschriften stark verbreitet ist, wird von ihm außer acht gelassen.

59 Vgl. zu dieser Entwicklung Colafrancesco Carletti 1995.

60 Hervorgehoben von Dinkler 1972, 484-487, der auf die vielschichtige Semantik von pax in den Grabinschriften hinweist; ähnlich Colafrancesco Carletti 1995, $270 f$.

61 Eine stärkere Akzentuierung der Jenseitigkeit tritt vor allem hervor in Wendungen wie dormit in

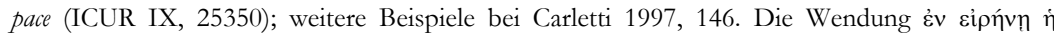

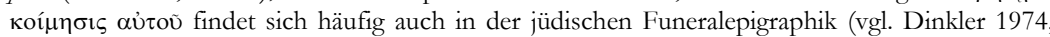
133f.). Ein Abhängigkeitsverhältnis der christlichen pax-Inschriften von jüdischen Vorbildern lässt sich nicht sicher erweisen; entscheidend ist in jedem Fall, dass der pax-Begriff im christlichen Kontext eine andere Bedeutung hatte als das jüdische beshalom (ebd. 138-143; weniger differenziert Dinkler 1972, 484).

62 Vgl. Pietri 1983, 557; Carletti 1988, 120. 
bei der Bestattung auch dem Toten erteilt wurde, ${ }^{63}$ und die Wiederaufnahme rekonzilierter Büßer in den „Frieden“ der christlichen Gemeinschaft ${ }^{64}$ - pax bezeichnet in all diesen Fällen nicht nur die äußere Einheit, sondern die sozialen Handlungen, die diese Einheit begründeten. ${ }^{65}$

Die Parallelen zum refrigerium liegen auf der Hand: In beiden Fällen signalisierte die Semantik der Begriffe, die in den Grabinschriften verwendet wurden, dass der Tote mit den Lebenden verbunden blieb. Sowohl pax als auch refrigerium bezeichneten einen Jenseitszustand der Ruhe und der Erholung von den Mühen des irdischen Daseins, doch hatten beide Begriffe zugleich einen starken sozialethischen Bedeutungsgehalt, der eine gegenläufige Deutungsebene wachrief: Der Tote in pace blieb Teil einer diesseitigen Gemeinschaft, deren Beziehungen nach ihrem Selbstverständnis von Liebe und Friedensbereitschaft geprägt war; der Tote in refrigerio erfuhr sein jenseitiges Dasein unter denselben Vorzeichen, unter denen sich die Kommemorierenden zur gemeinschaftlichen Feier des Totenmahls versammelten.

Die enge Zusammengehörigkeit von pax und refrigerium, die auch in einigen frühen Grabinschriften, in denen beide Begriffe miteinander verbunden werden, sichtbar wird, ${ }^{66}$ spiegelt dementsprechend nicht eine Vorstellung vom Tod als enthobenem Zustand des Friedens und der Ruhe wider, sondern bezog den Toten in Handlungszusammenhänge ein, die für den gemeinschaftlichen Zusammenhalt der Lebenden elementar und über die Grenze des

63 Metzger 1998, 46f. (Liturgie); Ambrosius verband mit dem Kuss für seinen toten Bruder Satyrus explizit den Gedanken der gemeinschaftsstiftenden pax in Gegenwart der Gemeinde: procedamus ad tumulum. sed prius ultimum coram publicum vale dico, pacem praedico, osculum solvo (Ambr., exc. Sat. 1, 78; weitere Belege bei Klauser 1927, 128, Anm. 107). Die Bedeutung der pax als eines die Lebenden und die Toten umfassenden Friedens wird während der diocletianischen Verfolgungen hervorgehoben von Arnob., nat. 4, 36: summus oratur Deus, pax cunctis et venia postulatur: magistratibus, exercitibus, regibus, familiaribus, inimicis, adbuc vitam degentibus et resolutis corporum vinctione. Zur Verbindung von pax im Leben und im Tod vgl. auch Tert., anim. 51, 6 und Cypr., epist. 57, 1 u. $55,17$.

${ }^{64}$ Bei der Wiederaufnahme der Sünder in die kirchliche Gemeinschaft erteilte der Bischof den Frieden (Tert., pudic. 12, 11; 22, 10; Cypr., epist. 20, 3; 36, 2; 64, 1; laps. 15); in Verbindung mit communicare/communicatio erscheint pax bei Tert., pudic. 6, 9; 13, 9-11; Cypr., epist. 55, 6; 72, 3. Tert., pudic. 2, 2 mahnt zur Friedfertigkeit als Voraussetzung für die Vergebung und Wiederaufnahme in die pax der kirchlichen Gemeinschaft (vgl. dazu die Bemerkungen von Poschmann 1940, 333f.).

65 Zur sozialethischen Dimension von pax bei Tertullian und Cyprian vgl. die Ausführungen von Pétré 1948, 300-303. Eine entsprechende Bedeutung des Friedens tritt auch im Hirten des Hermas deutlich hervor: Herm., vis. 3, 9, 2-6 leitet die Mahnung zum Frieden mit einer umfassenden Forderung nach sozialen Verhaltenstugenden (gegenseitige Sorge und Hilfe, insbesondere Armenunterstützung) ein (vgl. auch Brox 1991, 515f.). Zur Verbindung von pax und caritas, der tätigen Nächstenliebe, vgl. u., S. 54f.

66 In refrigerio et in pace z. B. in ICUR IX, 24906, 25455, die beide zum Inschriftenbestand des 3. Jh. zu zählen sind (vgl. Carletti 1988, 121). Eine Verbindung von pax und refrigerium mit Bezug auf den Jenseitszustand findet sich bereits bei Iren., haer. 3, 16, 4. 
Todes hinaus wirksam waren. ${ }^{67}$ Akklamationsartige Zurufe an den Toten (pax tecum, refrigera, pie zeses) stellten diese Beziehungen zwischen den Lebenden und den Toten explizit her: Die im Leben wirksamen Verbindungen dauerten im Tod fort. Die Betonung liegt dabei auf dem Aspekt der dadurch begründeten Handlungsbeziehungen zwischen Lebenden und Toten: Pax und refrigerium waren, wie oben ausgeführt, Begriffe mit starken sozialethischen Implikationen, die für das Selbstverständnis der Gemeinden eben deswegen von zentraler Bedeutung waren, weil sie das gemeinschaftserhaltende und -erzeugende Handeln der Gemeindemitglieder untereinander zum Ausdruck brachten. Bezogen auf die Toten bedeutet dies, dass auch sie mit der Welt der Lebenden durch Handlungsbeziehungen verbunden blieben. Dies wird insbesondere dort deutlich, wo Akklamationen wie refrigera oder pax tibi/ tecum, die als Grußformeln unter den Lebenden die Grundlagen sozialer Gemeinschaftsstiftung reflektieren, auch an die Toten gerichtet wurden, während man umgekehrt durch die Bitte an die Toten, sie mögen sich der Lebenden erinnern, ihnen helfen und beistehen, die Vorstellung artikulierte, auch die Toten seien weiterhin in ein Handlungsgefüge einbezogen, das die Sozialbeziehungen der christlichen Gemeinden im Diesseits strukturierte. ${ }^{68}$

Bestätigt werden diese Beobachtungen noch durch einen dritten, inhaltlich mit pax und refrigerium eng verwandten Schlüsselbegriff der christlichen Sozialordnung, der ebenfalls im Kontext der frühchristlichen Funeralkultur Roms eine prominente Rolle spielt: die agape bzw. caritas, die von Cyprian als fundamentum pacis bezeichnet wird. ${ }^{69}$ Zwar zählen Grabinschriften mit dem

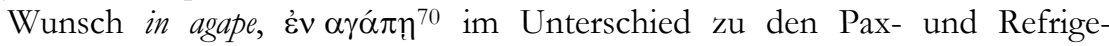
riuminschriften nicht nachweisbar zum ältesten Bestand der christlichen Sepulkralepigraphik Roms. Doch sind mehrere Darstellungen von Mahlszenen aus möglicherweise vorkonstantinischer Zeit in den römischen Katakomben erhalten, bei denen die Beischriften „Liebe“ (Agape) und „Frieden" (Irene) den Charakter der Mahlgemeinschaft signalisieren. ${ }^{71}$ Die von

67 Anders Janssens 1981, 292, der pax und refrigerium einseitig als „quiete del defunto in Dio“ auffasst. Auch Carletti 1988, 121 bezeichnet die Begrifflichkeit als „di tipo piu segnamente eschatologico."

68 Zum reziproken Charakter der Beziehungen zwischen Lebenden und Toten, wie er in der christlichen Funeralepigraphik Roms greifbar wird, vgl. Guyon 1987, 344-349. Für die Aufforderung zur Fürbitte, die die Lebenden an die Toten insgesamt - nicht nur an die Märtyrer - richteten; vgl. z. B. die bereits oben zitierte Inschrift: „Ianuaria, refrigeriere und bitte für uns“ (ICUR IV, 9913): Die Tote soll aus Dank für das Refrigerium für die Lebenden tätig werden, indem sie Fürbitte einlegt. Ähnlich auch die Inschrift ILCV 2336 (missverstanden von Volp 2002, 232f., Anm. 580, der den Handlungszusammenhang umkehrt, indem er diesen Inschriftentyp als eine Aufforderung, für die Toten zu beten, deutet).

69 Cypr., patient. 15: Caritas fraternitatis vinculum est, fundamentum pacis, tenacitas ac firmitas unitatis.

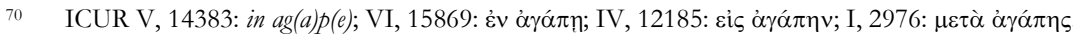

71 Eine überdurchschnittlich große Zahl von Mahldarstellungen ist aus der Katakombe SS. Pietro e Marcellino bekannt, darunter sämtliche acht Darstellungen mit den Beischriften Agape und Irene 
caritas (bzw. agape) und pax (oder irene) getragene Mahlfeier, zentrales Sinnbild für Handlungsbeziehungen und Gemeinschaftsstiftung im Diesseits, ${ }^{72}$ wurde durch die Darstellung im funerären Kontext auch auf den Toten bezogen.

Refrigerium, pax und caritas: Die zentrale Bedeutung dieser eng verwandten Begriffe in den Graffiti des Märtyrerkults, in der Sepulkralepigraphik und in den bildlichen Darstellungen im funerären Kontext weisen sämtlich in eine Richtung, die nochmals zusammenfassend skizziert werden soll: 1. Positiv besetzte, augurale Leitbegriffe des Diesseits wurden auf den Zustand der Toten bezogen. 2. Diese Begriffe hatten sozialethische Implikationen, sie regelten die Interaktion zwischen Menschen. 3. Sie waren verbunden mit Mahlfeiern, die im Gedenken an die Toten veranstaltet wurden (refrigerium bezeichnet ein Mahl; in den bildlichen Mahldarstellungen warten pax und caritas den Mahlteilnehmern auf). 4. Jenseitszustand und Gemeinschaftsstiftung im Diesseits waren nicht nur durch identische, die Grenze des Todes überspannende augurale Leitbegriffe miteinander verbunden, sondern auch durch Handlungsbeziehungen, die die sozialethischen Implikationen dieser Begriffe auf die Toten ausdehnten und diese durch reziproke Handlungsbeziehungen mit den Lebenden verbanden.

\section{2. Paganes und christliches Totenmahl}

Diese Beobachtungen legen es nahe, den christlichen Mahlfeiern am Grab der Toten und Märtyrer eine Semantik zuzuweisen, die das christliche Refrigerium von den paganen Totenkultriten prononcierter abhebt, als es in der Forschung allgemein üblich ist. ${ }^{73}$ So besteht in der Literatur ein maßgeblich von

(vgl. Février 1990 [1977], 360-368; Guyon 1977-78, 216-220; Jastrzebowska 1979, 19-29; ausführliche Beschreibung bei Dückers 1992, 147-159). Guyon 1987, 143f. veranschlagt für die beiden Regionen (A, I) in SS. Pietro e Marcellino, in denen sich die meisten dieser Mahlszenen konzentrieren, eine Entstehungszeit zwischen dem Ende des 3. und dem ersten Viertel des 4. Jh.; die cubicula, in denen die Mahlszenen dargestellt sind, datiert er in das beginnende 4. Jh. (vgl. Guyon 1994, 99f.). Deckers 1992, 231-235 zieht hingegen eine spätere Datierung vor und setzt die genannten Darstellungen erst in die konstantinische Zeit; ebenso zuletzt Zimmermann 2002, 235f. Eine umfassende Zusammenstellung christlicher und paganer Mahlszenen im funerären Kontext (Malerei und Sarkophagplastik) bietet Jastrzebowska 1979; vgl. Amedick 1991, 25-45. Agape und Irene werden in der Forschung traditionell auf die Dienerinnen - meist gedeutet als Personifikationen - bezogen, die den zum Mahl Versammelten aufwarten; anders Dückers 1992, 161f., der darauf aufmerksam macht, dass die Inschriften Agape und Irene nicht immer weiblichen Personen in den Mahldarstellungen zuzuweisen sind.

72 Zur Agape als Synonym für caritas vgl. Janssen 1938, 199-202. Zur zentralen Rolle der caritas/agape in christlichen Mahlfeiern vgl. Reicke 1951, 19-164.

73 Eine - die Regel bestätigende - Ausnahme bildet Pietri 1991, 28, der in den Refrigerien des 4. Jh. keine Übernahme paganer Praktiken sieht, sondern die Entwicklungformen eines eigenständigen Kults. 
Franz-Josef Dölger und Theodor Klauser begründeter, vor allem in der christlichen Archäologie verbreiteter und bis in die gegenwärtige Mediävistik reichender Konsens, dass das christliche Totenmahl nicht nur die äußeren Formen der paganen Totenmahlpraxis fortgesetzt, sondern auch in der Konzeptualisierung des Verhältnisses zu den Toten traditionelle Auffassungen fortgeführt habe. ${ }^{74}$ Fraglos trifft diese Einbindung der christlichen Totenmähler in das kulturelle Umfeld, in dem sie sich entwickelten, auf der Ebene der Praktiken zu; auch war das dezidierte Herausstellen dieser Kontinuitäten insbesondere in den $20 \mathrm{er}$ Jahren des vorigen Jahrhunderts als eine Reaktion auf Tendenzen, das christliche Totenmahl als eine Agapefeier, eucharistische Versammlung oder symbolische Jenseitsrepräsentation ohne einen Bezug zum paganen Umfeld zu deuten, verständlich. ${ }^{75}$ Dennoch ist zu berücksichtigen, dass diese Kontinuitäten in den Kultpraktiken sich nicht auch auf die Haltungen erstreckten, die die Lebenden gegenüber den Toten einnahmen: Im christlichen Totenmahl wird - bei allen äußeren Übereinstimmungen mit den Riten der paganen Tradition - eine grundlegend andere Relation der Lebenden zum Tod und zum Toten sichtbar.

Wie oben ausgeführt, blieb der Kommemorierte auch als Toter Teil der Gemeinschaft der Lebenden, die ihre Mahlgemeinschaft unter dieselben Leitbegriffe stellten wie den Jenseitszustand und durch entsprechende Zurufe und Bitten an die Toten diese in eine die Grenze des Todes überspannende, reziproke Handlungsgemeinschaft mit den Lebenden einbezogen. ${ }^{76}$ Dieses Verhältnis unterscheidet sich deutlich von der Relation, die - soweit sich das aus der lateinischen Sepulkralepigraphik und den römischen Totenkultriten erschließen lässt - der Tote nach paganen Vorstellungen zur Welt der Lebenden einnahm. Zwar ist es durchaus problematisch, von einer Geschlossenheit der religiösen Vorstellungen auszugehen, wie sie durch die Rede von „den“ paganen Jenseitsvorstellungen suggeriert wird. Zudem ist zu berücksichtigen, dass mit Blick auf den Tod und das Jenseits unterschiedliche Perspektiven (das Los des Verstorbenen neben der Rolle des Todes für die Überlebenden) und Haltungen (Furcht vor dem Tod; Trauer um den Verlust; Trost der Hinterbliebenen; Suggestionen und „echte“ Hoffnungen auf ein gutes Jenseits; memento mori, Lebensbejahung und Ironisierung des Todes) eingenommen werden können und ein Konglomerat bilden, das sich schwer zu einem konsi-

74 Dölger 1922, 562f.; Klauser 1927, bes. 54, 133-136; Marrou 1949, 196f., Jastrzebowska 1979, 89f.; dies. 1981, S. 205; Février 1984, bes. 167, 178. Für die Mediävistik vgl. Oexle 1983, 48-50; 1984 (a), 404-409; Borgolte 1988, 87.

75 Zum wissenschaftsgeschichtlichen Kontext der Debatte vgl. Dassmann, in: Colpe u. a. 1996, 397.

76 Die auch aus paganen Grabinschriften bekannten Aufforderungen, dem Toten zu trinken zu geben, begründen eine Partizipation, aber keine Mahlgemeinschaft des Toten mit den Lebenden. 
stenten Bild der Haltungen gegenüber dem Tod zusammenfügen lässt. ${ }^{77}$ Bei aller Vielfalt an Einstellungen zum Tod und zum Jenseits, die in den paganen Inschriften artikuliert werden, ${ }^{78}$ wird jedoch eines unmissverständlich deutlich: Der Tod markierte eine klare Grenze zur Welt der Lebenden und wurde ihr in den Äußerungen der Sepulkralepigraphik meist als eine regelrechte Gegenwelt des Nicht-Lebens (Nacht, Schatten, Schweigen) gegenübergestellt. ${ }^{79}$

Diese Grenze erlegte in Rom rituelle Regeln für den Umgang mit den Toten auf, die darauf abzielten, eine Befleckung der Welt der Lebenden durch die Toten möglichst auszuschließen. So waren etwa an den parentalia im Februar, den allgemeinen Festtagen zur Feier des Totenkults, die Tempel geschlossen, und es fanden keine Geschäfte statt: Die Unterwelt und die Welt der di superi durften sich nach Möglichkeit nicht berühren. ${ }^{80}$ Entsprechend waren auch die Bestattung und der Totenkult durchsetzt mit rituellen Handlungen, die eine deutliche Scheidung der Lebenden von den Toten durch eine doppelte Trennung vollzogen: Zum einen durch die Abgrenzung der trauernden Familie vom Toten, die während der eigentlichen Bestattung ihren Höhepunkt fand, und zum anderen durch die Separierung der durch den Toten befleckten Familie von ihrem sozialen Umfeld, die mit der Kennzeichnung des Hauses als domus funesta begann und mit der novemdialis cena endete, die die durch den Tod gestörte Einheit der Familie und der Gemeinschaft wiederherstellte. ${ }^{81}$

Mit diesen unterschiedlichen Riten von Abgrenzung und Integration waren auch unterschiedliche Arten der Mahlfeier und -gabe verbunden, die deutlich machen, dass es eine stark vereinfachende Verkürzung ist, mit Blick auf die traditionellen Mahlfeiern im römischen Totenkult von „dem“ Totenmahl zu reden. ${ }^{82}$ Das kultische Mahlopfer für den Toten und das Bankett der

77 Hervorgehoben von Pietri 1980; in modifizierter Form gilt dies auch für die christlichen Jenseitsvorstellungen.

78 Eine knappe, aber adäquate Übersicht vermittelt Pietri 1980, 31-35; ders. 1983, 536-548. Für weiteres Material vgl. besonders Brelich 1937, Lattimore 1942.

79 Vgl. dazu Brelich 1937, 5-31, der die Rede der lateinischen Grabinschriften vom Tod und der Unterwelt überzeugend als einen Versuch interpretiert, das Nicht-Sein als etwas, das dennoch existiert, positiv sprachlich verfügbar zu machen, indem man zur Welt des Lebens (Licht) Gegenbilder einer Nicht-Existenz (Schatten, Nacht, Schweigen) entwarf; s. auch Pietri 1983, 540542.

80 Scheid 1993, 197. Nur selten finden sich in den Grabinschriften Vorstellungen, die den di superi Macht über die Welt der Abgeschiedenen zusprechen (vgl. z. B. Pietri 1980, 32).

81 Zur Sequenz der römischen Bestattungsriten und dieser doppelten Absetzung der Lebenden von den Toten vgl. Scheid 1984; eine systematische Aufgliederung der einzelnen Separationsriten unternimmt Maurin 1984.

82 Dieser Sprachgebrauch und eine fehlende Differenzierung zwischen Totenopfer und Gedächtnismahl der Lebenden ist für die meisten Vertreter der o., S. 55f. skizzierten Kontinuitätsthese charakteristisch. 
Kommemorierenden waren nicht identisch, auch wenn sie bei der Gedächtnisfeier in einem engen zeitlichen und räumlichen Zusammenhang stehen konnten. ${ }^{83}$ Entsprechend ist es auch verzerrend, beide Elemente unter dem einheitlichen Begriff des Totenmahls zusammenzufassen, ohne die unterschiedlichen Ebenen auseinanderzuhalten: Im Unterschied zu den Mahlfeiern, zu denen die Hinterbliebenen im Gedenken an den Toten zusammenkamen, stiftete das Mahlopfer für den Toten - ob als silicernium bei der Bestattung oder als spätere Opfergabe bei den parentalia und anderen Totengedächtnistagen $^{84}$ - keine Mahlgemeinschaft mit ihm, im Gegenteil: Es akzentuierte die Grenze zwischen Leben und Tod. Bestimmte Traditionen des römischen Totenkults scheinen ein gemeinsames Mahl der Lebenden und der Toten sogar völlig auszuschließen, da das gesamte Opfer ausschließlich für den Toten bestimmt war. ${ }^{85}$

Die gemeinschaftlichen Totenmähler von kleineren Gruppen und Kollegien, auf die sich vor allem in der frühen Kaiserzeit archäologische und literarische Hinweise erhalten haben, ${ }^{86}$ sind demnach kein Ausweis dafür, dass man die Toten als Teilnehmer einer Mahlgemeinschaft der Lebenden vergegenwärtigte. Obwohl die Stiftungsinschriften der römischen Kaiserzeit zur Pflege des Totenkults und der Totenmemoria nur selten ausdrücklich zwischen einem epulum der Kommemorierenden und der profusio für den Toten als unterschiedlichen Handlungen differenzieren, ${ }^{87}$ handelte es sich um getrennte Dinge: Die Toten erhielten bestimmte, ihnen vorbehaltene Speisen, ihr Platz war nicht am Tisch der Lebenden, die Gaben für die Toten wurden

83 Die strukturelle Differenzierung zwischen Totenspeisungen und Gedächtnismählern der Kommemorierenden wird hervorgehoben von Andreau 1977, 160, 185f. und - für den griechischen Bereich - von Schmitt-Pantel 1982.

$84 \mathrm{Zu}$ den Parallelen der rituellen Handlungen und ihrer Abfolge bei der Bestattung und bei den regelmäßig wiederkehrenden Totenkultfeiern vgl. Scheid 1984, 132-136.

85 So z. B. beim Totenkultmahl des Pisanerdekrets für L. Caesar (vgl. Scheid 1993, 197f.); möglicherweise galten ähnliche Regelungen auch für das silicernium (vgl. Scheid 1984, 130).

86 Heinzelmann 2000, 70-72, 99; ders. 2001, 185-188; vgl. ferner Toynbee 1971, 62. Die in der Forschung von Theodor Mommsen begründete Auffassung, es habe in der Kaiserzeit collegia funeraticia gegeben, die eigens für die Bestattung ihrer Mitglieder gegründet worden seien, kann mittlerweile als überholt gelten: Die Bestattung von Vereinsmitgliedern und die Feier von Mählern im Gedenken an die Verstorbenen war nicht der Vergemeinschaftungszweck bestimmter „Begräbnisvereine“, sondern in den meisten Kollegien neben religiösen und sozialen Aktivitäten ein zentraler Bestandteil des Vereinslebens (grundlegend Ausbüttel 1982, 22-29, 59-71; vgl. zuletzt Bendlin 2002, 14; dens. 2005, 99).

87 Z. B. CIL X, 107 (epulum der Lebenden - profusio für den Toten). Vgl. auch die Stiftung des Q. Cominius Abascantus, in der zwischen einem epulum für die Kommemorierenden und einem sacrificium für den Toten unterschieden wird (s. u., S. 513f.). Eine der bekanntesten Memorialstiftungen (allerdings aus dem griechischen Bereich), die Stiftung des Epikur, differenzierte auch zeitlich zwischen dem Totenopfer für Epikur und seine Angehörigen auf der einen und den Mahlfeiern der Schüler zur Erinnerung an Epikur und Metrodoros auf der anderen Seite; die Feiern wurden an unterschiedlichen Tagen abgehalten (vgl. Laum 1914, Bd. 2, 16f., nr. 14). 
auf dem rogus oder in der culina verbrannt bzw. auf den Boden gestellt oder ausgegossen. ${ }^{88}$ Inschriftliche Aufforderungen der Toten, man möge ihnen etwas zu essen oder zu trinken geben, und entsprechende Zurufe der Lebenden an die Toten lassen sich daher nicht einfach als Ausdruck einer Mahlgemeinschaft mit den Toten interpretieren. ${ }^{89}$

Es gibt Anzeichen dafür, dass mit der ausgehenden hohen Kaiserzeit Vorstellungen von einem positiven Jenseitszustand zunehmend auch in der paganen Religiosität Raum gewannen: Mythologische und bukolische Darstellungen in der Grabkunst, die von der Forschung häufig als allegorische Verweise auf heroische Todesüberwindung bzw. ein glückliches Jenseits gedeutet werden, und die zunehmende Verbreitung von Mysterienkulten deuten auf einen entsprechenden Mentalitätswandel hin, auch wenn eine prospektive, auf das künftige Schicksal des Toten bezogene Lesart dieser Darstellungen umstritten bleibt. ${ }^{90}$ Selbst wenn man einen derartigen Wandel in den paganen Jenseitsvorstellungen der Kaiserzeit voraussetzt, ist damit jedoch noch nichts über die Relation der Lebenden und Toten zueinander gesagt. Die Vorstellung, dem Toten sei nach seinem Hinscheiden ein freundlicheres Dasein in einer jenseitigen Welt beschieden, schuf keine unmittelbare und distanzlose Verbindung zwischen Lebenden und Toten; sie vermittelte keinen gemeinsamen Handlungs- und Existenzzusammenhang. Der Tote blieb - ob als Schatten in der Unterwelt oder als vergöttlichte Seele in elysischen Gefilden prinzipiell außerhalb der menschlichen Gemeinschaft, die zur Feier der Totenmähler an den Gräbern der Verstorbenen zusammenkam. Eine positive Bewertung der Existenz nach dem Tod änderte nichts daran, dass zwischen beiden Welten eine klare Trennlinie bestand. Ähnlich wie im römischen Opfer für die di superi Vorbehalte zu erkennen sind, die Götter als Eingeladene und Tischgenossen der Menschen zu begreifen, ${ }^{91}$ bewegte sich auch der Tote bei den Mahlfeiern, die in Verbindung mit den römischen Totenkultpraktiken stattfanden, außerhalb der menschlichen Mahlgemeinschaft.

88 Scheid 1984, 127-134. Besonders ausgeprägt ist die Trennung bei den Lemuria: Hier vollzog sich das Mahlopfer in Abwendung vom Toten und ohne eigene Beteiligung des Opfernden am Mahl (ebd., 135f.).

89 Gegen Klauser 1927, 135f. Der dort zitierte Passus aus Epiph., anc. 86 steht in einem weiteren Kontext: Neben der Aufforderung an den Toten, er möge sich erheben und speisen, erwähnt Epiphanius kurz zuvor, dass die Speisen als Brandopfer oder Libationen vernichtet wurden: Diese Mahlgabe an den Toten war demnach keine Aufforderung zur Mahlgemeinschaft. Zu den Bitten der Toten um Speise und Trank in der lateinischen Sepulkralepigraphik vgl. Lattimore $1942,133$.

$90 \quad$ Vgl. Wrede 1981, 169; Amedick 1991, 17; Engemann, in: Colpe u. a. 1996, 302-309. Vorbehalte gegen allegorisierende Deutungen formuliert Heinzelmann 2000, 70f.; auch von Hesberg 1992, 216-221 betont die retrospektiven und diesseitsbezogenen Aspekte mythologischer Darstellungen an Gräbern.

91 Vgl. Rüpke 2001, $145 f$. 
Diese Einstellung zeigt sich insbesondere im Umgang mit dem toten Körper und den sterblichen Überresten des Toten. Die mythologischen und bukolischen Darstellungen, die den Toten in die Welt der Götter versetzten, basierten auf einer dualistischen Trennung der Seele vom toten Körper, der beim Aufstieg in den Himmel oder zu den Gefilden der Seligen zurückgelassen wurde. ${ }^{92}$ Damit aber fehlte eine wichtige Voraussetzung dafür, die Toten auch weiterhin als einen Teil der menschlichen Gemeinschaft zu begreifen. Die christliche Vorstellung einer körperlichen Auferstehung schuf in dieser Hinsicht vollkommen andere Grundlagen: Die Fortsetzung der irdischen Identität im Jenseits ließ die Vorstellung, dass die Toten, die nach ihrem Tod nicht entrückt wurden, sondern in ihren Leibern der Auferstehung harrten, ${ }^{93}$ in eine menschliche Handlungsgemeinschaft einbezogen blieben, in einer Weise evident erscheinen, die mit nicht-christlichen Vorstellungen nur schwer vereinbar war. Nichts macht diese Differenz deutlicher als der Umgang mit den sterblichen Überresten der Toten, die in ihren Leibern gegenwärtig und damit unter den Menschen präsent blieben. ${ }^{94}$ Der sich seit dem 4. Jh. entwickelnde christliche Reliquienkult bedeutete einen scharfen Bruch mit dem traditionellen antiken Prinzip einer klaren räumlichen Trennung, die zwischen den Lebenden in den Städten und den Toten in ihren Gräbern bestand und auch durch vereinzelte räumliche Annäherungen zwischen den beiden Welten ${ }^{95}$ nicht prinzipiell in Frage gestellt wurde. ${ }^{96}$ Die Schärfe dieses Bruchs macht zugleich deutlich, wie sehr die christliche Vorstellung einer Handlungsgemeinschaft der Lebenden und Toten auf spezifischen Voraussetzungen beruhte, die durch die kaiserzeitlichen Jenseitsvorstellungen - mochten sie auch ein positiveres Verhältnis zur Welt des Todes signalisieren - nicht infrage gestellt wurden.

92 Dies erhellt aus der paganen Funeralepigraphik, die komplementär zur Deutung der Grabsymbolik heranzuziehen ist, vgl. Brelich 1937, 76-86; Lattimore 1942, 28-43.

93 In den theologischen Auseinandersetzungen um die leibliche Auferstehung hoben insbesondere Theologen der westlichen Tradition (Tertullian, Hieronymus, Augustinus) auf eine materiale Wiederherstellung des irdischen Körpers aus seinen Partikeln ab, da nur auf diese Weise die Identität des Verstorbenen über die Grenze von Tod und Auferstehung hinweg gegeben erschien (vgl. Walker Bynum 1995, 21-114); derartige realistisch-materialistische Deutungen leiblicher Wiederauferstehung waren im 2. Jh. stark verbreitet (s. ebd., 27-33).

94 Zum christlichen Grab- und Reliquienkult als Konsequenz der Auffassung von der körperlichen Auferstehung der Toten vgl. Pietri 1991, 33.

95 Vgl. Bodel 1997, 20f. zu Gräbern, die in ländlichen Villen und auf Feldern angelegt wurden: Hier traten die räumlichen Abgrenzungen zwischen den Toten und den Lebensbereichen der Villenbesitzer bzw. der Landbevölkerung weniger deutlich hervor als in der Stadt.

96 Dieser Bruch wird zurecht hervorgehoben von Brown 1981, 6-8. Die syrische Didaskalie aus der ersten Hälfte des 3. Jh. lässt erkennen, dass die Einbeziehung der Toten selbst innerhalb der christlichen Gemeinden durchaus mit Widerständen rechnen musste (Didasc. 26; zum Kontext vgl. Karpinski 1987, 156-158). Auf welche Vorbehalte im 3. Jh. die Lehre von der leiblichen Auferstehung bei philosophisch gebildeten Römern stieß, zeigen die Worte, die Minucius Felix in seinem Dialog Octavius dem Heiden Caecilius in dem Mund legte (Min. Fel. 11, 2-9). 
Die unterschiedlichen Konzeptualisierungen des Verhältnisses der Lebenden zu den Toten hatten auch Auswirkungen auf die Frage, in welcher Weise die Erinnerung an die Toten und an die Heiligen zur Grundlage für kollektive Identitätskonstruktionen wurde. Das christliche hatte ebenso wie das pagane Totenmahl eine gruppenstabilisierende Funktion, da in ihm die Prinzipien von Einheit und Ordnung, auf die sich ihre Gemeinschaft gründeten - pax, refrigerium, caritas - den Feiernden vor Augen geführt wurden. ${ }^{97}$ Diese Prinzipien blieben jedoch nicht auf die Gemeinschaft der Kommemorierenden beschränkt, sondern wurden auf die Toten, die in diese Handlungsstruktur eingebunden blieben, ausgedehnt: Die Toten waren durch ihr Handeln (Interzession, Fürbitte) an der Vergegenwärtigung dieser Gruppenidentität aktiv beteiligt. Die Graffiti unter S. Sebastiano verdeutlichen diese Verbindung auch terminologisch, indem sie die Mahlgaben für die Apostel als ein refrigerium bezeichnen und dafür denselben Begriff verwenden, der auch für das Gedächtnismahl der Kommemorierenden in Gebrauch war: Im refrigerium wurde keine Absetzung vom Toten in Form eines Totenopfers vollzogen, sondern es entstand eine Verbindung von Lebenden und Toten unter den Vorzeichen eines gemeinsam begangenen Mahls.

Demgegenüber erfüllte auch das pagane Totenmahl eine identitätsrelevante Funktion, jedoch auf andere Weise:

1. In ritueller Hinsicht lässt sich das gemeinsame Mahl der Kommemorierenden im paganen Kult als eine postliminale Wiederherstellung der sozialen Ordnung der Hinterbliebenen begreifen, ${ }^{98}$ die durch den Einbruch des Todes gefährdet wurde, und deren Fundamente aus diesem Grund anlässlich der Kommemoration jedesmal aufs neue vergegenwärtigt und gesichert wurden eine Wiederherstellung der Ordnung, die jedoch nicht unter Einschluss, sondern in Ausgrenzung des Toten erfolgte.

2. Während in den christlichen Refrigerienfeiern für die Toten und Heili-

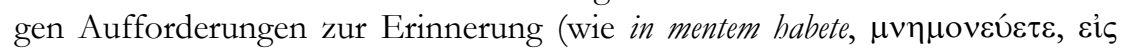

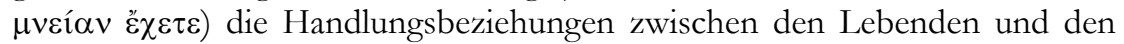
als gegenwärtig gedachten Toten aufrechterhielten, kam dem Erinnern und Gedenken in den paganen Kommemorationsmählern eine rein retrospektive Funktion zu: Man erinnerte und vergegenwärtigte die Toten als das, was sie gewesen waren.

Dies bringen insbesondere die Kommemorationsstiftungen, die im Westen des Römischen Reiches seit dem 2. Jh. aufkamen und Kollegien oder Munizipien mit der Feier des Andenkens eines Stifters beauftragten, zum

\footnotetext{
${ }_{97}$ Dieser identitätsstiftende Aspekt wird für das christliche wie nichtchristliche Totengedenken hervorgehoben von Février 1990 (1977); zu den Refrigerien s. ebd., 368-371 u. 375-390.

98 Vgl. Morris 1992, 8-10, der die Ritualstruktur eines „rite de passage“ zugrundelegt.
} 
Ausdruck. ${ }^{99}$ Entgegen älterer Auffassungen, die das Aufkommen dieser Stiftungen im kaiserzeitlichen Rom mit einem Verfall der Familiensolidarität in Verbindung brachten und die Schaffung künstlicher Familien wie Kollegien und Munizipien als Sorge des Stifters um den Fortbestand seines Grabkults interpretierten, ${ }^{100}$ sehen jüngere Deutungen diese Memorialstiftungen in einem engen Funktionszusammenhang mit dem Euergetismus: Die Mähler, die ein Stifter zu seinem Gedenken ausrichten ließ, waren keine sacra, die sich an ihn selbst richteten, sondern hielten das Andenken an die liberalitas des Stifters gegenwärtig. ${ }^{101}$ Man kann dies zu der Aussage zuspitzen, dass der Stifter durch die Ausrichtung von Mählern, die Verteilung von Natural-, Öl- und Geldspenden und die Abhaltung von Gladiatorenspielen über den Tod hinaus in seiner Eigenschaft als Euerget kommemoriert wurde. ${ }^{102}$ Memoria begründete in diesem Fall, anders als bei den Refrigerienmählern, keine gegenwärtig wirksame Interaktionsbeziehung zwischen den Kommemorierenden und den Toten, sondern hielt retrospektiv einen Handlungszusammenhang in Erinnerung, die zwischen dem Stifter und den Kommemorierenden zu Lebzeiten bestanden hatte. ${ }^{103}$ Dementsprechend fanden Gedenkfeiern für Tote und Stifter in der Regel nicht an deren Todes-, sondern Geburtstagen statt: ${ }^{104}$ Das Gedenken war auf den Lebenden beziehungsweise auf das, was der Tote zu seinen Lebzeiten gewesen war, zentriert.

99 Als Übersicht über die Stiftungen des Hellenismus und der römischen Kaiserzeit ist immer noch nützlich Laum 1914, Bd. 2; eine Zusammenstellung aller Stiftungen für das Italien der frühen und hohen Kaiserzeit bietet Andreau 1977.

100 So Bruck 1954, bes. 48-58; übernommen von Borgolte 1988, 77-79.

101 Andreau 1977; eine entsprechende Deutung für das hellenistische Griechenland vertreten Veyne 1990 (1976), 221-232; Schmitt-Pantel 1981.

102 Vgl. Champlin 1991, 161. Dies gilt auch für die Gedenkmähler, die sich nicht an größere Gruppen, sondern an einen begrenzten Kreis von Freunden und Familienangehörigen richteten, vor allem an Freigelassene, denen vom verstorbenen dominus in der Kaiserzeit häufig die Grabpflege und Kommemoration übertragen wurde (s. dazu Johnston 1988, 100-102). Vgl. die Bilanz von Champlin ebd., 181f.: ,the normal sentiment seems to have been, regardless of one's personal beliefs on the hereafter, that the survivors should have a good time eating and drinking (on whatever scale), put a generous portion on the grave, and then remember the deceased; the dead might be watching in the vicinity of the grave or statue, but the ceremony essentially concerned the living, who watched over, and remembered, them."

103 In dieselbe Richtung weisen Reliefs mit Mahlszenen an Gräbern, deren Teilnehmerkreis nicht familienbezogene Eigenschaften, sondern die liberalitas des Toten und seine Eigenschaft als Euerget festhielten (vgl. Compostella 1992). Z. T. wurden Stiftungen zur jährlichen Feier des Geburtstages noch zu Lebzeiten eingerichtet und dann nach dem Tod des Stifters weitergeführt (vgl. Schmidt 1906, 50).

104 Vgl. Schmidt 1906, bes. 47-52. 


\section{3. Der römische Märtyrerkult des 3. Jh. zwischen Fragmentierung und Gemeinschaftsstiftung}

Mahlfeiern wie die unter S. Sebastiano bezeugten refrigeria im Gedenken an die Apostel Petrus und Paulus sind demnach als Ausdruck einer spezifisch christlichen Vorstellung anzusehen, wonach Lebende und Tote über die Grenze des Todes hinweg in einem Handlungszusammenhang miteinander verbunden waren. Im folgenden wird $\mathrm{zu}$ diskutieren sein, welche Auswirkungen diese Konzeptualisierung eines grenzüberschreitenden Handlungszusammenhangs auf die Entwicklung der Märtyrerverehrung während des 3. Jh. und auf die Sozialbeziehungen innerhalb der christlichen Gemeinden in dieser Zeit hatte. Zu diesem Zweck ist es notwendig, sich zunächst einige Grundlinien der Entwicklung der Heiligenverehrung zu verdeutlichen.

Das Bild der Heiligen wurde seit der Mitte des 3. Jh. wesentlich bestimmt von ihrer Eigenschaft, als Interzessoren für das Seelenheil ihrer Mitchristen eintreten zu können. ${ }^{105}$ Aus der sündenvergebenden Kraft des Martyriums einer Vorstellung, die etwa seit der Mitte des 2. Jh. begegnet - erwuchs den Heiligen die Möglichkeit, durch ihr Blutzeugnis nicht nur für sich selbst die Sühnung von Sündenschuld zu erwirken, sondern auch für andere Gemeindemitglieder einzutreten und als fürbittende Interzessoren tätig zu werden. ${ }^{106}$ Besonders während der decischen und valerianischen Verfolgungen, als zahlreiche Bekenner vom Glauben abgefallene Christen in den Kirchenfrieden aufnahmen, wurde diese interzessorische Fähigkeit der Heiligen zur Sündenvergebung betont und entwickelte sich nicht selten zur Quelle von Konflikten mit der amtskirchlichen Buß- und Vergebungspraxis. Vor allem die Korrespondenz des Bischofs Cyprian v. Karthago gibt einen Einblick in das Ausmaß, in dem während der 250er Jahre in Nordafrika und Rom Fragen der Bußdisziplin und der interzessorischen Tätigkeit von Confessoren und Märtyrern virulent wurden. ${ }^{107}$

105 Zur verstärkten Akzentuierung des Interzessionsgedankens, der andere Aspekte des Martyriums wie den Zeugnis- und Vorbildcharakter stärker in den Hintergrund drängte, vgl. allgemein Martin 1990, 443-448; Pietri 1991, 24-26.

106 Vgl. die umfangreiche Materialzusammenstellung bei Dassmann 1973, 153-182. Besonders ausgeprägt ist die theologische Reflexion des Sühne- und Interzessionsgedankens bei Origenes; vgl. ebd., 166-168, 176-178; Rordorf 1972.

107 Anders als in Nordafrika, wo Cyprian wiederholt die aus seiner Sicht allzu große Bereitwilligkeit zahlreicher Bekenner kritisierte, in den Gefängnissen Friedensbriefe für lapsi auszustellen, ohne dass diese die erforderliche Bußleistung erbracht hatten, vertraten die Confessoren in Rom möglicherweise eine eher rigoristische Haltung. Dies gilt zumindest für eine Bekennergruppe um den römischen Gegenbischof Novatian (250-258), die in Fragen der Kirchenbuße eine außerordentlich harte Position bezog, da sie bußfertigen lapsi nicht in jedem Krankheitsfall, sondern nur in Todesgefahr die Rekonziliation gewähren wollte (vgl. Vogt 1968, 37-45). 
Diese mit der verstärkten Akzentuierung des Interzessionsgedankens einhergehende Spannung im Verhältnis zur amtskirchlichen Vergebungspraxis hatte tiefgreifende Folgen auch für die in der Heiligenverehrung wirksamen Kommunikations- und Handlungsbeziehungen und für die Rolle der Heiligen als Bezugspunkte kollektiver Identitätsstiftung. Spätestens seit der Wende vom 2. zum 3. Jh. waren in Rom - ähnlich wie in anderen kirchlichen Gemeinden des Mittelmeerraums - geregelte Verfahren der postbaptismalen Buße entwickelt worden, die der pastoralen Einsicht Rechnung trugen, dass die einmalige Sündenvergebung in der Taufe den Gemeindemitgliedern keine Heilsgewissheit vermittelte, sondern sie vielmehr der prekären Lage aussetzte, für schwere Vergehen, die sie sich nach der Taufe zuschulden kommen ließen, keine Vergebung erwarten zu können. ${ }^{108}$ Die Kirchenbuße sollte getauften Christen auch bei Glaubensabfall und schweren sittlichen Verfehlungen noch eine zweite Möglichkeit eröffnen, Vergebung für ihre Sündenschuld zu erhalten, knüpfte dies allerdings an strenge Voraussetzungen. Die Bußfertigen mussten zunächst vom Bischof akzeptiert und in den ordo paenitentium aufgenommen werden und hatten daraufhin - je nach der Schwere des Vergehens - Bußstufen unterschiedlicher Dauer zu durchlaufen. Dabei mussten die Büßer sich vor der Gemeinde öffentlich als solche bloßstellen und das fürbittende Gebet ihrer Mitchristen erflehen, bevor sie durch die Handauflegung des Bischofs rekonziliert wurden. ${ }^{109}$

Kennzeichnend für diese durch die Kirchenbuße erwirkte Sündenvergebung war ihre feste institutionelle Einbindung in die Gemeindestrukturen. Der bischöflichen Autorität des Gemeindeleiters oblag die disziplinäre Aufsicht über den Bußakt und die als heilssichernd verstandene Wiedereingliederung in die Gemeinde, die den durch die Schuld herbeigeführten Ausschluss aus der kirchlichen Gemeinschaft wieder rückgängig machte. Gleichzeitig trug während des Bußaktes das Gebet der Gemeinde wesentlich dazu bei, die Vergebung des Büßers vor Gott zur erwirken: Der öffentliche Charakter der paenitentia publica fand eben darin seine Begründung, dass der Büßer durch seine Bloßstellung vor der Gemeinde an deren Fürbitte und Unterstützung in seinen Anliegen appellierte.

Dieses Prinzip, die Sündenvergebung in der Struktur der Gemeinde zu verankern, wurde dadurch, dass sich einzelne Gemeindemitglieder an Confes-

108 Grundlegend zur postbaptismalen Buße, deren Anfänge wohl noch in die apostolische Zeit zurückreichen, während die frühesten Quellen zum Bußverfahren erst um 200 fassbar werden, ist immer noch Poschmann 1940. Zur Situation in der römischen Gemeinde, wo die umstrittene Handhabung der Kirchenbuße unter Bischof Kallixt (217-222) zur Bildung einer Sondergemeinde unter dem Presbyter Hippolytus führte, vgl. ebd., 348-367.

109 Die Bußstufen sahen vor, dass die Büßer zunächst außerhalb des Kirchenraums Aufstellung nahmen, bevor ihnen der Zutritt zur Gemeindeversammlung gewährt wurde; vgl. Poschmann 1940, 316f. (Tertullian). Zur Verdemütigung der Büßer vor der Gemeinde und der Bitte um Fürbitte s. ebd., $483 \mathrm{f}$. 
soren und Märtyrer als persönliche Fürsprecher wandten, in mehrfacher Hinsicht durchbrochen. Die Fürbitte war nicht mehr eine kollektive Angelegenheit der Gemeinde, sondern das Werk einzelner Interzessoren, denen aufgrund ihrer Martyriumsbereitschaft eine besondere Nähe zu Gott attestiert wurde. Gleichzeitig wurde die Vergebung der Sündenschuld durch Gott als das wesentliche Moment aufgefasst: Die episkopale Wiederaufnahme der Sünder in den Frieden der kirchlichen Gemeinschaft verlor damit zwar nicht an Bedeutung, wurde jedoch nicht mehr für sich genommen als heilssichernd verstanden, sondern ergab sich als Konsequenz aus der durch die Interzessoren bei Gott erwirkten Sündenvergebung. ${ }^{110}$ Das von amtskirchlicher Seite vorgebrachte Argument, die Interzession der Heiligen werde möglicherweise in Gottes Gegenwart beim Endgericht wirksam, könne jedoch keinen Einfluss auf die Gemeindeordnung haben, ${ }^{111}$ bringt die divergierenden Auffassungen auf den Punkt: Einer durch Mittlergestalten zwischen der göttlichen und menschlichen Welt verbürgten Vergebung der Schuld stand das Prinzip gegenüber, dass das Heil nur durch die Zugehörigkeit zur Kirche erlangt werden könne.

Diese Rolle der Märtyrer als Mittler zwischen Gott und den Menschen eröffnete den lapsi die Möglichkeit, ihre Sorge um das eigene Heil individuell, außerhalb der durch den Bischof repräsentierten Gemeinschaft der Gemeinde zu suchen. In einem anregenden Beitrag zur Geschichte der spätantiken Heiligenverehrung hat Jochen Martin die historischen Dimensionen dieser fragmentierenden Tendenz nachdrücklich dadurch herausgestellt, dass er sie als Ausdruck eines allgemeinen Mentalitätswandels deutet: ${ }^{112}$ Die in der Akzentuierung der Interzessions- und Mittlerfunktion der Märtyrer begegnende Anschauung, Autorität nicht mehr sozial, sondern religiös zu begründen, sei Ausdruck eines allgemeinen Mentalitätswandels und zeige sich auch im Selbstverständnis und der Repräsentation der Kaiser des 3. Jh., die als gottbeauftragte Herrscher agierten und damit in eine ähnliche Mittlerposition zwischen göttlicher und menschlicher Welt eingerückt seien wie die Heiligen. Das damit verbundene Herausheben aus menschlichen Kommunikationsbeziehungen und die Berufung auf eine von Gott verliehene Autorität habe im politischen wie im kirchlichen Bereich - eine grundlegende und vor allem auf lange Sicht wirksame Schwächung von innerweltlich begründeten Hand-

110 In der Praxis äußerte sich diese Sichtweise in der Regel darin, dass die Confessoren den lapsi sogenannte Friedensbriefe ausstellten und die Priester und Bischöfe autoritativ zur Wiederaufnahme und formalen Rekonziliation der abgefallenen Gemeindemitglieder auf dieser Grundlage aufforderten (als Beispiel für eine derartige „Anweisung“vgl. Cypr., epist. 23). Daneben gehen manche Äußerungen von Confessoren sogar dahin, die Sündenvergebung in eigener Person, ohne eine amtskirchliche Vermittlung, vorzunehmen (vgl. Cypr., epist. 21, 3, 2).

111 So Cypr., laps. 17; vgl. Dassmann 1973, $173 \mathrm{f}$.

112 Vgl. zum folgenden Martin 1990, bes. 459-462. 
lungsbeziehungen zur Folge gehabt, in den christlichen Gemeinden ebenso wie in den Städten des Imperium Romanum, in denen die bis dahin maßgebliche Vorstellung von der städtischen Gemeinschaft als eines euergetischen Handlungszusammenhangs verloren gegangen sei.

Es kommt im folgenden nicht darauf an, die umfassende historische Triftigkeit dieses Modells zu diskutieren, sondern es umgekehrt - im Sinne von Webers idealtypischer Methode - als ein heuristisches Instrument zu verstehen und auf den empirischen Detailbefund der Graffiti unter S. Sebastiano zu beziehen. ${ }^{113}$ Die entscheidende Frage wird dabei sein, inwieweit der Zusammenhang zwischen einer in den Heiligen als Interzessoren und Mittlern wirksamen Hierarchisierung und der Fragmentierung von Handlungsbeziehungen idealtypisch „richtig“ (d. h. hinreichend komplex) konstruiert erscheint, oder ob die Refrigerien unter S. Sebastiano Anlass geben, das Modell zu erweitern und zu modifizieren.

Zunächst ist festzuhalten, dass der Zusammenhang zwischen dem Einrücken der Märtyrer in eine Mittlerposition zwischen göttlicher und menschlicher Welt und der damit einhergehenden Schwächung sozialer Handlungsbeziehungen zwar gedanklich überzeugend und konsequent konstruiert ist, in den Befunden der Triklia an der via Appia jedoch nur bedingt Rückhalt erfährt. Fraglos signalisiert der Begriff des votum, also der kultischen Weihung an eine Gottheit, ${ }^{114}$ und die Betonung der Fürsprache in den Graffiti für Petrus und Paulus, dass den Märtyrern eine besondere Macht zugeschrieben wurde, die sie tendenziell aus den menschlichen Handlungsbeziehungen heraushob. Dennoch blieben sie eingebunden in einen sozialen Handlungszusammenhang von Menschen, deren Beziehungen untereinander - gekennzeichnet durch refrigerare, pax, agape - auch das Verhältnis zu den Toten im allgemeinen und den Märtyrern als den besonderen Toten bestimmten. Die Haltung der Kommemorierenden gegenüber den Märtyrern lässt sich daher auch kaum als die passiver Empfänger einer göttlich vermittelten Gnade 115 interpretieren: Wie bereits gesehen, waren nicht passiver Empfang, sondern die Betonung reziproker Handlungsbeziehungen für das refrigerare, ebenso wie für die pax und die caritas konstitutiv. Die Ebene sozialer Handlungsbeziehungen wurde durch die kultische Märtyrerverehrung also nicht nur nicht verlassen, sondern im Gegenteil besonders hervorgehoben. Dieser Aspekt der

113 Zur idealtypischen Methode s. auch u., S. 509, Anm. 19.

114 Für die Bezeichnung der Refrigerien als vota für die Apostel s. o., Anm. 36. Zur Bedeutung von votum als kultische Weihung vgl. Latte 1976, 46f. Votum begegnet zwar vereinzelt auch in Grabinschriften, bezogen auf normale Tote, doch handelt es sich hier um einen poetischen Wortgebrauch (vgl. Lattimore 1942, 133f.).

115 Zum Aspekt von Aktivität - Passivität vgl. die Bemerkungen von Martin 1990, 446, der es der Akzentuierung des Interzessionsgedankens zuschreibt, dass sich die Relation zwischen den Märtyrern und den normalen Gemeindemitgliedern zu einem asymmetrischen Verhältnis „zwischen Aktiven und Passiven“ entwickelt habe. 
Gemeinschaftsstiftung äußerte sich sowohl im Verhältnis der Kommemorierenden zu den Märtyrern als auch in der Feier des Refrigeriums, das nach Ausweis der Graffiti, in denen häufig mehrere Personen die Apostel um Fürbitte angingen, offenbar in der Regel in Gruppen gefeiert wurde.

Man kann über diese Feststellung, dass die Semantik von refrigerare/refrigerium darauf hinweist, dass die Heiligen fest in den Zusammenhang innerweltlicher Handlungsbeziehungen integriert blieben, noch ein Stück hinausgelangen, indem man die Natur dieser Beziehungen noch genauer zu bestimmen versucht. Soziale Handlungsbeziehungen können sehr unterschiedliche Abstufungen im Grad der Hierarchisierung zwischen den Beteiligten beinhalten: Reziprozität ist nicht gleichbedeutend mit Symmetrie. Im folgenden soll daher, ausgehend vom Wortgebrauch von refrigerare in der passio Perpetuae, der Versuch unternommen werden, diese soziale Relation genauer zu fassen, die zwischen den Märtyrern und denen, die unter S. Sebastiano Refrigerien für sie feierten, bestand. ${ }^{116}$

Refrigerare ist in der passio Perpetuae siebenmal belegt; davon zweimal in einer reflexiven bzw. intransitiven Bedeutung von „sich ausruhen“ oder „sich erholen“, in der kein Handlungszusammenhang zu erkennen ist. ${ }^{117}$ In der bereits erwähnten Vision des Saturus, die die Märtyrer im Paradies mit den irdischen Streitigkeiten der Gemeinde von Karthago konfrontierte, liegt der Fall etwas anders. Die Engel ermahnen die streitenden Parteien, sie sollten die Märtyrer „refrigerieren“ lassen und, falls sie Auseinandersetzungen haben, einander vergeben: sinite illos refrigerent; et si quas habetis inter vos dissensiones, dimittite vobis invicem. ${ }^{118}$ Auch hier ist das refrigerare intransitiv verwendet, der Kontext legt jedoch nahe, dass damit mehr als nur ein ,ausruhen“ gemeint ist. Das refrigerare der Märtyrer wird dem Streit der verfeindeten Kleriker entgegengehalten, deren gegenseitige Vergebung (dimittite vobis invicem) - so die implizite Schlussfolgerung - auch ihnen ein refrigerium bereiten könnte. Beim refrigerium der Märtyrer handelt es sich damit nicht nur um den künftigen paradiesischen Jenseitszustand der Märtyrer, sondern auch um ein irdisches Gegenbild zu den dissensiones, die durch gegenseitige Vergebung überwunden werden sollen. ${ }^{119}$

Diese implizite Bedeutung von refrigerare im Sinne einer gegenseitigen Vergebung wird durch weitere Stellen der passio Perpetuae, in denen die soziale Handlungsdimension des Worts ausdrücklich hervortritt, bestätigt. Geradezu wie eine Übersetzung der Saturusvision in die Gegenwart der Märtyrer im

\footnotetext{
116 Zu den methodischen Voraussetzungen, die ein Heranziehen der Passio Perpetuae zur Klärung des Sprachgebrauchs der römischen Graffiti ermöglichen, vgl. u., S. 72f.

117 Pass. Perp. 3, 4; 8, 1.

118 Ebd., 13, 5.

119 Zur visionären Verschränkung der Zeitrelationen zwischen der Gegenwart der Märtyrer im Gefängnis und ihrer zukünftigen Vollendung nach dem Martyrium s. o., S. 50 f.
} 
Gefängnis Karthagos wirkt eine Bemerkung Perpetuas, die eingekerkerten Märtyrer und die Besucher, denen der Zugang erlaubt worden war, hätten sich gegenseitig (invicem) gestärkt: qui (scil. der praepositus carceris) multos ad nos admittebat, ut et nos et illi invicem refrigeraremus. ${ }^{120}$ Refrigerare konstituiert hier als ein sozialer Akt der gegenseitigen Tröstung und Stärkung die Beziehungen zwischen den Märtyrern und ihrem Umfeld. Dass zur Bezeichnung dieser Relation hier der Begriff refrigerare verwendet wird, ist kein Zufall; er scheint für die Kommunikation zwischen den lebenden Märtyrern und den Personen, die sie im Gefängnis aufsuchten, ein regelrechter terminus technicus gewesen zu sein. Noch an zwei weiteren Stellen der Passio Perpetuae werden derartige Visiten der Märtyrer im Gefängnis mit der Feststellung eines refrigerare verbunden. ${ }^{121}$ Auch die Akten der Märtyrer Montanus und Lucius, die 259 während der valerianischen Verfolgung ums Leben kamen, berichten ebenfalls, die eingekerkerten Märtyrer seien einige Tage lang durch den Besuch ihrer Glaubensgenossen gestärkt worden (refrigeravimus). ${ }^{122}$

In allen diesen Beispielen berührt refrigerare einen Handlungszusammenhang, der zwischen den Märtyrern und den Personen, die sie während der Verfolgung in den Gefängnissen und der Vorbereitung auf das Martyrium aufsuchten, wirksam wurde. Es ist zwar kein Begriff, der - im Gegensatz etwa zur caritas - soziale Relationen notwendig beinhaltete: Perpetua konnte sich einfach nur durch die Abwesenheit ihres Vaters stärken, ohne dass refrigerare hier eine soziale, zwischen Menschen begründete Handlungsdimension hätte. ${ }^{123}$ Dennoch ist unverkennbar, dass refrigerare in der Bedeutung als Tröstung oder Stärkung als anschauungsleitend für die Relation angesehen wurde, die zwischen den Märtyrern und der sozialen Umgebung ihrer Besucher bestand. Diese Relation war bestimmt von einem komplexen Verhältnis wechselseitiger Verdemütigung und Ehrzuweisung, die eine spezifische Kommunikation zwischen den Märtyrern und denen, die sie in den Gefängnissen aufsuchten, begründete. Der Grund dafür ist in der prekären Situation

120 Pass. Perp. 9, 1.

121 Zwei Diakone erwirken durch Bestechungsgelder, dass die Märtyrer kurzzeitig an einem besseren Ort „refrigerieren“ (ebd. 3, 7: tunc Tertius et Pomponius, benedicti diaconi qui nobis ministrabant, constituerunt praemio uti paucis horis emissi in meliorem locum carceris refrigeraremus). Der Begriff fällt in einer ähnlichen Situation, als es den Brüdern Perpetuas und weiteren Besuchern erlaubt wird, das Gefängnis zu betreten und sich zusammen mit den Märtyrern zu stärken (ebd. 16, 4: tribunus... iussit illos (scil. Perpetua und ihre Begleiter) bumanius haberi, ut fratribus eius (scil. Perpetua) et ceteris facultas fuerit introeundi et refrigerandi cum eis).

122 Actus Luci et Montani 4, 7: paucis diebus visitatione fratrum refrigeravimus. Die Authentizität der Actus wird von Teilen der Forschung sehr skeptisch beurteilt (vgl. zuletzt die Zweifel von Duval 2000, 433). Es ist jedoch nicht einzusehen, warum die Abhängigkeiten der Actus vom CEuvre Cyprians und von der Passio Perpetuae ein Argument gegen ihre Entstehung im direkten historischen Zusammenhang mit den berichteten Ereignissen darstellen (so auch Dolbeau in seiner Einleitung zu den Actus, 1983, 39f.).

123 Pass. Perp. 3, 4: paucis diebus, quod caruissem patrem, Domino gratias egi et refrigeravi absentia eius. 
der martyres designati ${ }^{124}$ zu suchen, deren bevorstehendes Martyrium durch den vorzeitigen Tod im Gefängnis, durch Entlassung oder durch die Kapitulation vor Todesfurcht und Schmerz ständig gefährdet erschien. Die frühen Märtyrerakten berichten wiederholt davon, dass manche Märtyrer sich noch im letzten Moment gegen das Sterben entschieden, den Foltern nicht gewachsen waren oder das Martyrium nicht erlitten, weil das Urteil aufgehoben wurde. ${ }^{125}$ Der schrittweise Kampf des Märtyrers gegen die Versuchungen während der Haft bildete bereits einen wesentlichen Teil des Martyriums, das in der Hinrichtung seine Vollendung erfuhr: Die Gefährdungen auf diesem Weg waren Stationen eines Agons, dessen sicheres Ende erst mit dem Tod erreicht wurde. ${ }^{126}$ Insbesondere Cyprian hat diese prekäre Situation der noch nicht vollendeten Märtyrer als Argument gegen die Ausstellung von Friedensbriefen aufgegriffen, indem er von den Eingekerkerten Demut forderte und ihre vergebende Haltung als hochmütige Vorwegnahme des noch keineswegs sicheren Martyriums kritisierte. ${ }^{127}$

In dieser agonalen Vorbereitung auf die Hinrichtung spielte die Hilfe, die den Märtyrern durch die materielle Unterstützung und durch die Gebete von Besuchern zuteil wurde, eine wichtige Rolle. Bereits Tertullian erwähnt mehrfach die Besuche von Klerikern und Gemeindemitgliedern in den Gefängnissen und verstand seine eigene Schrift an die Märtyrer als einen geistigen Beistand, um sie in ihrem Martyriumsentschluss zu bestärken. ${ }^{128}$ Cyprian zeigte sich in gleicher Weise überzeugt, durch seine Briefe an die Märtyrer in den

124 Der Ausdruck stammt von Tert., mart. 1, 1.

125 M. Polyc. 2f.; Eus., h. e. 5, 1, 11f., 25, 27f., 33-35, 45f., 48, 50 (Märtyrer von Lyon); Pass. Mar. Iac. 10 (Aufschub des Martyriums). Die Frage, ob es Martyrium ohne die Vollendung geben könne, war umstritten; Cyprian sah sich veranlasst, die Gültigkeit auch dieses Martyriums zu betonen (Cypr., epist. 61, 2).

126 Die Heilssicherheit des durch das Martyrium erlangten Todes ist ein zentrales Motiv im Briefwechsel Cyprians, z. B. epist. 6, 3: das Martyrium ist „der Ruhm der ewigen Freiheit und Sicherheit“; epist. 10, 5: ,sicherer ist es, mit der Vollendung des Sieges eiligst zum Herrn zu gelangen, freudenreicher ist es, wenn man nach der rühmlichen Tat noch eine Frist erhält und das Lob der Kirche genießen darf" (scil. als Confessor). Zur Sicherheit des Heils als zentrales Anliegen vgl. auch Cypr., epist. 11, 8; 59, 8. Diese Akzentuierung der securitas gegen die Gefährdung durch Schuld steht in direktem Zusammenhang mit den Verfolgungen der 250er Jahre und den dadurch ausgelösten Problemen des Abfalls großer Teile der christlichen Gemeinden; auch die außergemeindliche Wüstenaskese, die in der zweiten Hälfte des 3. Jh. ihren Ursprung hat, ist bestimmt vom Streben, einen sicheren Weg zum Heil zu finden (vgl. Frank 51993, 16f.).

127 Cypr., epist. 6, 3. In epist. 13, 3 ermahnt Cyprian die Märtyrer, ,auf dem schmalen und engen Pfad des Lobes und des Ruhmes" (in arto et in angusto itinere landis et gloriae) zu bleiben und sich in Demut zu üben.

128 Tert., mart. 1, 1; vgl. ebd. 2, 7 (materielle Liebesgaben der Mitbrüder: per curam ecclesiae et agapen fratrum); Tert., uxor. 2, 4, 2; sowie die etwa zeitgleiche Pass. Perp. 3, 7. Kritisch zur übertriebenen Fürsorge für die Märtyrer in den Gefängnissen äußerte sich Tert., ieiun. 12, 3. Für die Mitte des 3. Jh. vgl. ferner Cypr., epist. 14, 2; 15, 1. Zur Besuchspraxis in den römischen Gefängnissen s. weiteres Material bei Krause 1996, 122-127 u. 288-291. 
Gefängnissen einen Dienst an ihnen und ihrem Willen zum Martyrium zu leisten. ${ }^{129}$ Auch von den Märtyrern selbst wurde die fürbittende und helfende Kraft dieser Besuche und Gebete hervorgehoben. Der noch aus dem 2. Jh. stammende Gemeindebrief über eine Christenverfolgung in Lyon 177/178 berichtet, die Eingekerkerten hätten es strikt abgelehnt, sich vor ihrem Tod als Märtyrer bezeichnen zu lassen, und stattdessen ihre Brüder gebeten, sie möchten „flehentlich um ihre Vollendung beten“. ${ }^{130}$ Im Briefwechsel Cyprians sind mehrere Briefe von Confessoren erhalten, in denen sie dem Bischof für seine Unterweisung und materielle Unterstützung danken und ihn weiterhin um sein Gebet für die Vollendung ihres Martyriums bitten. ${ }^{131}$

Diese Beispiele mögen genügen, um das besondere Verhältnis zu erfassen, in dem die Märtyrer und die Gemeindemitglieder, die sie im Gefängnis aufsuchten, standen. Ihre Besucher sahen in den Märtyrern bereits vor ihrem Tod die Gegenwart einer besonderen göttlichen Gnade wirksam, begegneten ihnen daher mit besonderer Ehrerbietung und trugen an die martyres designati die Bitte heran, für die Vergebung ihrer Sünden bei Gott einzutreten und ihnen so erneut die Aufnahme in die kirchliche Gemeinschaft zu ermöglichen. ${ }^{132}$ Umgekehrt baten aber auch die Märtyrer um die Fürsprache ihrer Glaubensgenossen und mussten ihrerseits eine demütige Haltung an den Tag legen, um nicht den erfolgreichen Kampf gegen den Widersacher durch Stolz auf die eigene Leistung zu gefährden. Die daraus resultierende wechselseitige Zuweisung von Verdemütigungsgesten konnte offenbar mitunter ritualisierte Formen annehmen. ${ }^{133}$ So begegnete in den Lucius und Montanus-Akten der Märtyrer Lucius noch am Ort der Hinrichtung der Bitte der anwesenden Christen, ihrer zu gedenken, mit der Erwiderung, sie mögen umgekehrt seiner gedenken. ${ }^{134}$ Diese Praxis und der anschließende Kommentar des Verfassers

129 Cypr., epist. 37, 1.

130 Eus., h. e. 5, 2, 2f.

131 Cypr., epist. 31 und 77, 78, 79. Der Bischof ist den Bekennern in „wechselseitiger Liebe“ verbunden (vgl. die Eröffnung der epistula ad Silvanum, Reginum et Donatianum (CC 3, 659): Ciprianus dominis meis fratribus sanctissimis atque dilectissimis incomparabili caritate et mutua dilectione connexis).

132 Schon bezeugt von Tert., mart. 1, 5: quam pacem quidam in ecclesia non habentes a martyribus in carcere exorare consueverunt, vgl. auch Tertullians scharfe Kritik an dieser Praxis während seiner montanistischen Phase in pudic. 22, $1 \mathrm{f}$.

133 Ein eindrückliches Beispiel für eine solche Ritualisierung gegenseitiger Demutsbezeugung bietet der römische Bußritus, wie ihn Soz., h. e. 7, 16 um die Mitte des 5. Jh. beschreibt: Der ordo paenitentium warf sich nach der Feier des Gottesdienstes unter Seufzen und Stöhnen zu Boden, was der römische Bischof dadurch beantwortete, dass er sich seinerseits unter den Tränen der Gemeinde vor den Büßern niederwarf. Der Grad an performativer Routine war hier jedoch wesentlich stärker als in den Gefängnissen des 3. Jh.: Die gegenseitige Verdemütigung im römischen Bußritus beruhte auf regelmäßig wiederholten und in ihrem Verlauf erwartbaren Gesten. Im Gegensatz dazu war die Verdemütigung des Märtyrers charakterisiert durch eine in ihrem Ausgang offene, nicht rituell kontrollierbare Situation, nämlich das bevorstehende Martyrium.

134 Actus Luci et Montani 13, 5f.: cui (scil. Lucius) cum dicerent fratres: Memento nostri, Vos, inquit, mei mementote. quanta martyris humilitas, de gloria sua thec solit nec sub ipsa passione praesumere. Das nec soli 
der Akten („Wie groß war die Demut des Märtyrers, nicht einmal an der Schwelle zum Tod etwas von seinem Ruhm vorwegzunehmen“) führen nahezu idealtypisch die sozialen Beziehungen zwischen dem Märtyrer und seiner Umgebung sowie die Deutungen, die die Märtyrerakten von diesem Verhältnis verbreiteten, vor.

Diese spezifischen Kommunikationsbeziehungen zwischen den Märtyrern und ihrer Umgebung, die auf gegenseitiger Verdemütigung beruhten und eine hierarchische Relation tendenziell ausschlossen, fanden in der pax ihren deutlichsten - und nachhaltigsten - Ausdruck: Der Friede, in den die Märtyrer denjenigen, die sie aufsuchten, aufzunehmen pflegten, ${ }^{135}$ war der sichtbare Ausdruck dieser von Demut als Leitvorstellung geprägten Kommunikation. Der Bericht über die Märtyrer von Lyon stellt den Zusammenhang explizit her:

„Sie (scil. die Märtyrer) hatten sich unter die gewaltige Hand Gottes gedemütigt, von der sie jetzt so sehr erhöht worden sind. Für alle wussten sie damals Entschuldigungen und niemanden klagten sie an. Alle lösten sie, niemanden banden sie.“136

Beiderseitige Demutshaltungen - das Nachsuchen um Vergebung auf der einen, Vergebungsbereitschaft auf der anderen Seite - begründeten einen Gemeinschaftszusammenhang der $p a x$, auf dessen sozialethische Implikationen bereits hingewiesen wurde.

Es ist dieser Kontext wechselseitiger Demutsbezeugungen und der daraus erwachsenden Einheitsstiftung, in den auch das gemeinschaftliche refrigerare der Märtyrer und ihrer Umgebung, von dem die Märtyrerakten berichten, einzuordnen ist. Da die Besucher den Märtyrern offenbar häufig durch Speisen und materielle Unterstützung Erleichterung verschafften, liegt es nahe, unter den Refrigerien im wesentlichen Mahlfeiern zu verstehen, ebenso wie auch die refrigeria im Toten- und im Märtyrerkult unter S. Sebastiano Mahlspenden waren. In den Lucius und Montanus-Akten wird zudem die Speisung der Märtyrer durch einen Besucher ausdrücklich als ein refrigerium bezeichnet. ${ }^{137}$ Dabei lässt sich die Bedeutung dieser Speisung nicht auf einen reinen Akt materieller caritas für Notleidende reduzieren. Von frühchristlicher Zeit an stand das gemeinsame Mahl im Zentrum kollektiver Identitätsstiftung in

wird nur von einem Teil der Handschriften überliefert und ergibt zudem inhaltlich keinen Sinn (vgl. die Edition von Dolbeau 1983, 75, Anm. 37); es wurde daher in der obigen Übersetzung nicht berücksichtigt.

135 Vgl. dazu - neben den Märtyrern von Lyon - exemplarisch die Actus Luci et Montani 13, 6: Die Märtyrer ermahnen ihre Mitbrüder zur pax (ähnlich 14, 7); 18, 4: Flavianus will jedem in Fuscianum den Frieden erteilen; ebd. 23, 1-3: Flavianus erteilt direkt vor dem Martyrium allen den Frieden und fordert sie dazu auf, ecclesiae pacem et dilectionis unitatem zu bewahren. Zu den Friedensbriefen, die die Confessoren in den Gefängnissen ausstellten, vgl. die umfangreiche Materialsammlung und -diskussion bei Poschmann 1940, 270-283.

136 Eus., h. e. 5, 2, 5.

137 Actus Luci et Montani 9. 
den christlichen Gemeinden, ${ }^{138}$ und die durch die eucharistische Feier vermittelte communio entwickelte sich in der Folge zum konstitutiven Element für deren Selbstverständnis und Gemeinschaftsbegriff. ${ }^{139}$ Auch nachdem sich die Eucharistie, in der diese communio wirksam wurde, von ihrer ursprünglichen Verbindung mit dem Sättigungsmahl der Agape zu lösen begonnen hatte, blieb deren einheits- und gemeinschaftsstiftende Mahlsymbolik auch in nichteucharistischen Mahlformen erhalten. ${ }^{140}$ Vor dem Hintergrund dieser Symbolik erhielt auch das gemeinsame Mahl, das die Märtyrer mit den aus der Kirchengemeinschaft ausgeschlossenen Sündern in den Gefängnissen hielten, eine hohe Integrationsfunktion. Die communio im gemeinsamen Mahl war gleichzeitig der sicht- und erfahrbare Ausdruck des Friedens, den die Märtyrer denjenigen erteilten, die sie aufsuchten: Die Mahlspende durch die Besucher wurde erwidert durch die Aufnahme in die Mahlgemeinschaft durch die Märtyrer. ${ }^{141}$

$138 \quad$ Meeks 1983, 102f.

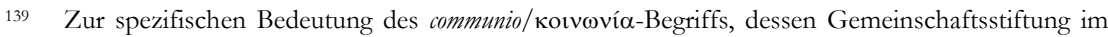
Unterschied zur societas nicht auf einem Zusammenschluss, sondern auf der Vorstellung der eucharistisch vermittelten - Partizipation am Leib Christi gründet, vgl. Eizenhöfer 1956, 24-26, Benko 1964, 79-90. Zur fundamentalen ekklesiologischen Bedeutung der eucharistischen Mahlgemeinschaft („Kirchengemeinschaft ist Abendmahlsgemeinschaft“) vgl. Kretschmar 1977 (a), 75f.; einschlägige Quellenbelege bei Eizenhöfer 1956, 26-33.

140 Zur Trennung von Agape/Sättigungsmahl und Eucharistie s. Meyer 1989, 106 mit Verweis auf Hipp., trad. ap. 26, wo der Unterschied zwischen eucharistischer Gabe ( $\varepsilon \dot{\chi} \chi \alpha \rho \imath \sigma \tau i \alpha)$ und geseg-

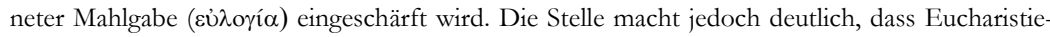
und Agapefeier weiter miteinander verbunden blieben; auch deutet gerade die Bemühung um eine klare Abgrenzung darauf hin, dass eine solche Trennung zwar angestrebt wurde, jedoch in der allgemeinen Vorstellung der Zeit noch nicht verankert war (in diesem Sinne auch Stuiber 1966, 915). Dasselbe gilt auch für das Verbot von Laieneulogien (Hipp., trad. ap. 28), die den Mahlfeiern der Märtyrer in den Gefängnissen nahe gekommen sein müssen. Die historische Einordnung der traditio apostolica bereitet Probleme, da sie in der jüngeren Forschung nicht mehr dem römischen Presbyter Hippolytus, der als Gegner des Bischofs Kallixt (217-222) auftrat und 235 gemeinsam mit Bischof Pontianus aus Rom verbannt wurde, zugesprochen wird; man geht davon aus, dass eine nicht näher lokalisierbare Grundschrift in der Zeit vor den großen Verfolgungen in der Mitte des 3. Jh. entstanden ist (vgl. zuletzt Markschies 1999, 49-53). Trotz dieser Zuordnungsprobleme, die eine präzise Einordnung spezifischer Angaben der traditio zur Gemeindeliturgie erschweren, spricht nichts dagegen, das Zeugnis der Schrift für allgemeinere Phänomene wie den hier diskutierten Zusammenhang von Mahlfeier und Gemeinschaftsstiftung heranzuziehen.

141 Zur Bedeutung der Mahlfeier im skizzierten Sinne vgl. auch die Bemerkung des Dionysius von Alexandria zur Problematik, den lapsi den von den Märtyrern gewährten Frieden nicht zu erteilen: „Sie (scil. die Märtyrer) nahmen dieselben auf, verkehrten mit ihnen, gaben ihnen Empfehlungen und ließen sie an ihren Gebeten und Mahlzeiten teilnehmen.“ (Eus., b. e. 6, 42, 5). Tert., mart. 2, 5 bezeichnet die Gaben der Gemeindemitglieder für die Märtyrer als agape - auch in diesem Ausdruck tritt nicht der materielle Aspekt der Speisung, sondern zugleich der der Mahlgemeinschaft hervor (vgl. Janssen 1938, 199-202, der allerdings die zitierte Stelle nicht als konkrete Agapefeier auffasst, m. E. zu Unrecht, da im Kontext davon die Rede ist, was „das Fleisch im Kerker einbüßt“"). Vgl. in diesem Zusammenhang auch die Pass. Perp. 17, 1: Die Märtyrer feierten anstelle der Henkersmahlzeit (cena libera) eine agape. Das Kapitel 17 schließt unmittelbar an eine 
Eine entscheidende Frage ist, ob zwischen dem refrigerare der Märtyrerakten und den gleichnamigen Totenmählern, für die kommemorierten Märtyrer, wie sie durch die Graffiti unter S. Sebastiano bezeugt werden, ein unmittelbarer Zusammenhang besteht. Es spricht viel für diese Annahme. Zwar ist es grundsätzlich methodisch problematisch, die Terminologie unterschiedlicher Diskurse - eines literarischen (Märtyrerakten) und eines alltagssprachlich-epigraphischen (Graffiti) - miteinander zu verbinden, da die Begriffe unterschiedlichen Voraussetzungen entspringen und dementsprechend auch unterschiedliche Bedeutungen haben können. Im hier interessierenden Fall dürften diese Bedenken allerdings unbegründet sein. Wie bereits erwähnt, taucht der Begriff refrigerium besonders häufig in der passio Perpetuae et Felicitatis auf. Bekanntlich hat der Verfasser der Passio nach eigenen Angaben auf zwei Aufzeichnungen der Märtyrer Perpetua und Saturus zurückgegriffen, in denen sie selbst über ihre Erlebnisse und Visionen im Gefängnis berichteten. ${ }^{142}$ Mehrere der oben zitierten Passagen zum refrigerium im Gefängnis lassen sich damit auf den Sprachgebrauch der Märtyrer selbst zurückführen, die darin eine allgemein übliche Bezeichnung für die gemeinsamen Mahlfeiern mit ihren Besuchern festgehalten haben dürften. ${ }^{143}$ Hinzu kommt, dass die Visionen der Perpetua und des Saturus sprachgeschichtlich typische Beispiele für die lateinische Umgangssprache des frühen 3. Jh. darstellen. Insbesondere die Aufzeichnungen der Perpetua vermitteln durch ihren konzeptionell oralen, linearen und parataktischen Stil Einblick in stilistische und sprachliche Eigentümlichkeiten des sermo cotidianus. ${ }^{144} \mathrm{Ihr}$ Idiom entspricht damit dem der Besucher, die unter S. Sebastiano ihre Graffiti an die Wände der Triklia

als refrigerium bezeichnete Mahlfeier der Märtyrer mit den Brüdern der Perpetua und weiteren Besuchern (ebd. 16, 4) an; der Verfasser der Passio leitet von diesem refrigerium zur agape über mit einem quoque: „Auch noch an dem Tag vor ihrer Hinrichtung... feierten sie eine Agape.“ Auch das zuvor erwähnte refrigerium hatte dementsprechend den Charakter einer Agapefeier.

142 Ebd., 3-10 (Bericht der Perpetua), eingleitet vom Redaktor mit der Bemerkung: haec ordinem totum martyrii sui iam binc ipsa (scil. Perpetua) narravit, sicut conscriptum manu sua et suo sensu reliquit (ebd., 2, 3) und 11-13 (Vision des Saturus). Bei beiden Visionen dürfte es sich um Dokumente handeln, die der Verfasser der Passio zusammenfügte, ohne sie zu überarbeiten (vgl. Amat [1996], in: Pass. Perp., 70-75).

143 Pass. Perp. 9, 1; 13, 5. Entsprechendes gilt auch für die Actus Luci et Montani 4, 7 und 9, 2. Da die Passio Perpetuae sowohl in einer lateinischen als auch in einer griechischen Version überliefert ist, ist umstritten, in welcher Sprache die Aufzeichnungen von Perpetua und Saturus ursprünglich abgefasst waren; vor allem die Lückenhaftigkeit des griechischen Textes gegenüber der lateinischen Fassung spricht jedoch dafür, dass die lateinische Variante die originale ist (für ein griechisches Original hat zuletzt Bowersock 1995, 33f. plädiert; einen Überblick über die Geschichte der Kontroverse bietet Amat [1996], in: Passio Perpetuae, 50-55; zu den Argumenten für eine Priorität der lateinischen Fassung vgl. ebd., 55-66).

144 Vgl. Shaw 1993, 19f.; Amat (1996), in: Passio Perpetuae, 70f. Bowersock 1995, 34 bezweifelt mit guten Gründen die Möglichkeit, im Perpetuabericht über den umgangssprachlichen Stil hinaus Spuren einer spezifisch weiblichen Sprache entdecken zu können (so Shaw) - es existieren keine antiken Vergleichsbeispiele, die diese Annahme untermauern könnten. 
schrieben. Da zudem auch bestimmte Wendungen in den Graffiti auf afrikanische Einflüsse hindeuten, ${ }^{145}$ erscheint der Vergleich zwischen der Begrifflichkeit in den Märtyrerakten und den Refrigeriumgraffiti methodisch unbedenklich: Mit der Bezeichnung refrigerare für die gemeinsamen Mahlfeiern verwendeten die Märtyrer ebenso wie die Besucher unter S. Sebastiano einen aus dem alltäglichen Sprachgebrauch vertrauten Begriff. Dass die Verwendungsweise in den Märtyrerakten und in den Graffiti unabhängig voneinander auf der Basis eines gemeinsamen umgangssprachlichen Substrats (refrigerare als allgemeine Bezeichnung für „erfrischen“) erfolgte, ist zwar nicht sicher auszuschließen, allerdings auch nicht wahrscheinlich. Vielmehr ist davon auszugehen, dass sich die „Erfrischungen“ zu einem regelrechten terminus technicus für die mit den Märtyrern gefeierten Mählern in den Gefängnissen entwickelten.

Es steht ferner außer Zweifel, dass die Besuche bei den Märtyrern in den Gefängnissen, die den Anlass für die Feier der Refrigerien bildeten, eine verbreitete Praxis während der Verfolgungszeiten waren. ${ }^{146}$ Dafür sprechen nicht nur die ausgedehnten innerkirchlichen Debatten um die Vergebungsbereitschaft der Märtyrer während der decischen und valerianischen Verfolgung, die das Phänomen aus der Perspektive der Bischöfe formulierten und - da sie ihre Autorität in der Bußdisziplin in Frage gestellt sahen - möglicherweise disproportional verzerrten. Bemerkenswert erscheint vielmehr, dass die Besuche in den Gefängnissen auch in der paganen Außenperspektive deutliche Spuren hinterlassen haben. In seiner Satire über den Kyniker Peregrinus Proteus zeichnet Lukian eine ausführliche Karikatur dieser Kommunikation des Märtyrers mit der Außenwelt: Peregrinus, der sich zwischenzeitlich auch mit

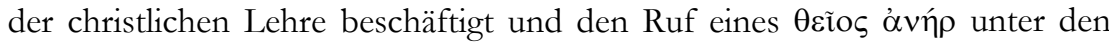
Gemeinden Palästinas und Syriens erworben hatte, wurde während einer Gefängnisstrafe zum Mittelpunkt eines regen sozialen Lebens: Man brachte ganze Nächte bei ihm zu, trug Speisen bei ihm zusammen und führte heilige Gespräche. ${ }^{147}$ Offensichtlich waren derartige Vorgänge in der Zeit nach 167, als Lukian seine Satire verfasste, so verbreitet, dass sie ohne weiteres parodiefähig waren. Diese Praktiken hatten bis zur Zeit der diokletianischen Verfolgungen nichts an Popularität verloren. Als Licinius in den 320er Jahren die Christenverfolgungen im Osten erneut aufnahm, erließ er ein Gesetz, das sich ausdrücklich gegen den Besuch der Märtyrer in den Gefängnissen richtete: Niemand solle ,sich gegen die Unglücklichen in den Gefängnissen durch die Verabreichung von Speise menschenfreundlich zeigen noch derer, die in Fesseln an Hunger dahinsiechten, sich erbarmen“. ${ }^{148}$

145 Ferrua 1965, 141.

146 Für entsprechende Belege christlicher Quellen vgl. Dassmann 1973, 179f.; McGowan 2003.

147 Luc., Peregr. 11-13.

148 Eus., h. e. 10, 8, 11. 
Die Refrigeriengraffiti unter S. Sebastiano, die bald nach 258, wohl zum größten Teil von einer Generation, die die decischen und valerianischen Verfolgungen noch selbst miterlebt hatte, an die Wände der Triklia geschrieben wurden, stammen aus einer Zeit, in der die Erinnerung an diese Besuche während der Verfolgungszeit noch sehr lebendig war. Es erscheint demnach mehr als naheliegend, dass die refrigeria, die die Besucher der Triklia feierten, in direkter Beziehung zu den gleichnamigen Mahlfeiern standen, die in der Kommunikation der lebenden Märtyrer mit ihrem Umfeld eine so zentrale Rolle gespielt hatten. Dass Petrus und Paulus, an die sich die Refrigerien im Hof unter S. Sebastiano richteten, nicht - oder zumindest nicht ausschließlich - als Gründer der römischen Kirche, sondern als Märtyrer verehrt wurden, zeigt ihre Anrede als martyres in einigen der Graffiti. ${ }^{149}$ Man bezog ihnen gegenüber dementsprechend dasselbe Verhältnis, das auch die Interaktion mit den Märtyrern während der Verfolgungszeit bestimmt hatte.

Dennoch ist die Kommunikationssituation, die für die Refrigerien während der Verfolgungen vor allem der 250er Jahre kennzeichnend gewesen war, nicht einfach auf die Zeit des sogenannten kleinen Kirchenfriedens, der durch die Edikte des Gallienus eingeleitet wurde, ${ }^{150}$ übertragbar. Während der Verfolgungszeit hatte das refrigerium einen reziproken Kommunikations- und Interaktionszusammenhang zwischen den noch nicht vollendeten Märtyrern und den sie besuchenden Gemeindemitgliedern begründet, der in dieser Form im Gedenken an einen verstorbenen Märtyrer nicht wirksam werden konnte. Mit dem Tod des Märtyrers fiel ein zentrales Element der ursprünglichen Handlungsbeziehung weg, nämlich das Handeln des Märtyrers, das zu Lebzeiten die ihm entgegengebrachte Verehrung seinerseits durch eine Geste der Verdemütigung beantwortet hatte. Auf diese Weise wurde eine Distanzierung der Heiligen in Gang gesetzt, die sie, wie es die Graffiti unter S. Sebastiano signalisieren, zu einseitigen Empfängern von vota machte: ${ }^{151}$ Die toten Heiligen konnten - anders als zu ihren Lebzeiten - der Verehrung durch ihre Mitchristen kein „Korrektiv“ entgegensetzen, das ihre Einbeziehung in einen reziproken Handlungszusammenhang betont hätte. In Nichtverfolgungszeiten, in denen die Refrigerienfeiern in den Gefängnissen nicht mehr zum Erfahrungshorizont der Gemeinden gehörten, veränderte sich auch die soziale

149 ICUR V, 12955: [sa]nti martyres [Paule] Pe[tre]; 12996 sa[ncti Paule et] Petr[e beati] martyres]; vgl. auch 12951 und 13002; daneben werden Petrus und Paulus auch als Apostel bezeichnet (vgl. o.). Zum Verhältnis von Apostel-, Märtyrer- und Bischofsverehrung in Rom vgl. o., S. 24, Anm. 74.

150 Vgl. Eus., h. e. 7, 13; zur juristischen Bewertung vgl. zuletzt Bendlin 2005, $103 \mathrm{f}$.

151 Betont auch von Jastrzebowska 1981, 205, die der Ansicht ist, die Märtyrer seien bei den Refrigerien in der Triklia unter S. Sebastiano nicht als Mahlteilnehmer, sondern als distanzierte Interzessoren betrachtet worden. Jastrzebowskas These, dies stelle einen Unterschied zum paganen Totenmahl dar, ist allerdings nicht nachvollziehbar: Das pagane Totenmahl begründete keine Mahlgemeinschaft zwischen Lebenden und Toten. 
Semantik der in einem anderen kommunikativen Kontext entstandenen Feiern: Das refrigerium begann sich zum votum zu wandeln. ${ }^{152}$

Diese Beobachtung gibt Anlass, die oben referierte These von der fragmentierenden Wirkung der Interzessoren auf die christlichen Gemeinden des 3. Jh. nochmals auf ihre Voraussetzungen und konkreten historischen Ausprägungen hin zu überdenken. Die besondere Fähigkeit der Märtyrer zur Interzession und deren proleptische Vorwegnahme bereits vor dem Jüngsten Gericht bewegte sich nicht nur in äußerer Konkurrenz zur - disziplinär wie pragmatisch - in der Gemeinde verankerten Bußform der paenitentia publica, sondern beruhte auch auf grundlegend anderen kommunikativen Voraussetzungen: Das Anliegen, Vergebung und Heilsgewissheit nicht mehr in der Gemeinde, sondern bei individuellen Fürsprechern vor Gott zu suchen, trug zweifellos eine Tendenz zur Schwächung der christlichen Gemeinden als Handlungsgemeinschaften in sich. Dieses fragmentierende Potential wurde jedoch zu denjenigen Zeiten, in denen die Kommunikation und Interaktion mit den Märtyrern von den Erfahrungen im Umgang mit noch nicht vollendeten Blutzeugen bestimmt war, nur begrenzt wirksam. Die ostentativen Gesten der Verdemütigung, die die martyres designati gegenüber ihren Mitchristen vollzogen, wirkten ihrer Entrückung in eine Mittlerstellung zwischen Gott und der menschlichen Welt entgegen: Die Märtyrer betonten, dass sie Teil einer reziproken Handlungsgemeinschaft waren, und machten das Gelingen ihres Blutzeugnisses ihrerseits von der Unterstützung und Fürbitte ihrer Besucher abhängig, die um die Fürsprache der Heiligen nachsuchten.

Ihre fragmentierende Wirkung entfaltete die Interzessionskraft der Heiligen erst unter der Voraussetzung, dass das Heiligengedenken nicht mehr in diesen reziproken Handlungszusammenhang eingebunden war, und dass sich in den Refrigerien eine Kommunikation mit den Heiligen vollzog, die die Bitte um Fürbitte zu einer - unter soziologischen Gesichtspunkten - einseitigen Angelegenheit machte. Zwar war die Vorstellung, dass Lebende und Tote in einer die Grenze des Todes überspannenden Handlungsgemeinschaft standen, die wesentliche Bedingung der Möglichkeit dafür, dass man sich mit der Bitte um Hilfe an die toten Heiligen wenden konnte: Die gemeinschaftliche Verbundenheit mit den Mitchristen - das wesentliche Begründungsmoment für die Entstehung der Fürbitte überhaupt ${ }^{153}$ - blieb nach christlicher Auffassung auch nach dem Tod erhalten und wirksam und führte im 4. Jh. dazu,

152 Für diesen Transformationsprozess ist dementsprechend zweitrangig, dass zwischen Petrus und Paulus und den Besuchern der Triklia ein reziproker Handlungszusammenhang niemals bestanden hat, da die beiden Gemeindegründer ihr Martyrium bereits um die Mitte des 1. Jh. erlitten hatten: Entscheidend war wohl weniger, ob man im refrigerium mit einem lebenden oder toten Heiligen kommunizierte, als vielmehr die Frage, ob der kulturelle Kontext, der die Semantik der Refrigerienfeiern bestimmte, von der Erfahrung der Kommunikation mit lebenden oder toten Heiligen geprägt war.

153 Dassmann 1973, 163 
dass sich die Heiligen zu allzuständigen Fürsprechern und Patronen nicht nur in Fragen der Sündenvergebung, sondern auch in zeitlichen Angelegenheiten entwickelten. ${ }^{154}$ Mit Kommunikation und Interaktion im Sinne eines soziologisch analysierbaren Handlungszusammenhangs hat diese Beziehung zu den Heiligen freilich nichts zu tun - im Unterschied zu den Refrigerien während der Verfolgungen, bei deren Gelegenheit sich komplexe Mechanismen wechselseitiger Verdemütigung zwischen den angehenden Märtyrern und ihren Besuchern entwickelten. Die Graffiti unter S. Sebastiano machen deutlich, dass dieses Verhältnis zu den Heiligen noch in frischer Erinnerung war - und signalisieren gleichzeitig die Richtung, die das Heiligengedenken und die als vota verstandenen Refrigerien unter den Bedingungen einer Friedenszeit nehmen sollten.

\section{4. Ergebnisse}

Die als refrigeria bezeichneten Mahlfeiern, die in der Triklia an der via Appia während der zweiten Hälfte des 3. Jh. gefeiert wurden, zählen nicht nur zu den frühesten Belegen für kultische Formen der Heiligenverehrung in Rom. Sie vermitteln zugleich zentrale Einblicke in die Grundlagen der christlichen Toten- und Heiligenmemoria und in die Wandlungsprozesse, die das Heiligengedenken unter den Bedingungen einer Übergangsphase erfuhr, als es sich aus den Voraussetzungen einer noch zu Lebzeiten erfahrbaren dynamischen Kommunikation mit den Märtyrern löste und rituelle Kommunikationsformen hervorbrachte, die es im kulturellen Gedächtnis der christlichen Gemeinden verankerten.

Im schillernden Begriff des refrigerium, das sowohl den Jenseitszustand der Toten als auch die Mahlfeiern, die die Lebenden im Gedenken an die Verstorbenen abhielten, bezeichnete, spiegelt sich der Umstand wider, dass in der christlichen Memorialkultur beide Bereiche nicht als raum-zeitlich klar voneinander geschiedene Welten betrachtet wurden. Märtyrerakten des frühen 3. Jh. machen ebenso wie sepulkrale Inschriften und Graffiti deutlich, dass zwischen diesseitigem und jenseitigem Refrigerium nicht nur eine äußere terminologische Übereinstimmung, sondern eine innere Verbindung bestand: Im jenseitigen Refrigerium begegneten die Märtyrer Handlungssituationen, die ihre Kommunikation mit den Gläubigen im Diesseits - vorzugsweise in den ebenfalls als Refrigerien bezeichneten Mahlfeiern mit ihren Mitchristen in den Gefängnissen - bestimmten; in inschriftlichen Anrufen wurden die Toten aufgefordert, am Refrigerium derer, die ihrer gedachten, teilzunehmen. Das

154 Diese Verbindung wird zurecht betont von Martin 1990, 461, der die Entwicklungen des 3. Jh. als zentrale „Ausgangsvoraussetzung für die später den Heiligen zugeschriebene Macht“ begreift. 
refrigerium gehört damit in den weiteren Kontext vergleichbarer Begriffe wie pax und caritas, die für das Leben der christlichen Gemeinden von zentraler Bedeutung waren und in der während des 3. Jh. entstehenden christlichen Sepulkralepigraphik als augurale Leitbegriffe auch über die Existenz der Toten gestellt wurden. Charakteristisch ist, dass es sich sowohl bei der pax als auch bei der caritas und dem refrigerium um Begriffe mit einer ausgeprägt sozialethischen Dimension handelt, die das füreinander verantwortliche und gegenseitige Handeln der Gemeindemitglieder thematisierten. Die Heiligen blieben damit, wie die Toten insgesamt, einbezogen in ein semantisches Bezugssystem von Handlungsbegriffen, die das Leben der Gemeinden regelten und über die Grenze des Todes hinaus auch auf die Toten ausgedehnt wurden. Unter diesen Voraussetzungen war das Totengedenken kein rein retrospektives Erinnern an das, was der Tote einst zu seinen Lebzeiten gewesen war, sondern Ausdruck der Vorstellung, mit den Toten auch in der Gegenwart in einem reziproken Handlungszusammenhang verbunden zu sein.

Eine vergleichbare Stellung kam den Toten in den römischen Totenkultriten und in der paganen Kommemorationspraxis nicht zu. Zwar hatte auch hier das vergegenwärtigende Erinnern an den Toten eine hohe identitätsrelevante Bedeutung für die Gruppen, die Träger dieser Erinnerung waren. Diese kollektive Identität wurde jedoch nicht dadurch begründet, dass man den Toten weiterhin als einen handlungsmächtigen Teil der Gruppe auffasste, sondern dadurch, dass man ihn retrospektiv in seinen sozialen Funktionen und Bezügen kommemorierte, die (beispielsweise als Familienangehöriger oder als Euerget) für seine Relation zu den Lebenden kennzeichnend gewesen waren. Anders als in der christlichen Memorialkultur verblieb der Tote damit außerhalb des Handlungszusammenhangs derer, die zu seinem Gedenken zusammenkamen. Mahlfeiern des christlichen Toten- und Heiligengedenkens wie die Refrigerien sind demnach - trotz äußerer Übernahmen - nicht einfach als eine Fortsetzung paganer Kultmähler anzusehen. In der Tradition des römischen Totenkults stellten Mahlfeiern keine Handlungsgemeinschaft zwischen den Welten der Lebenden und der Toten her: Die Opfergabe für den Toten machte ihn nicht zum Teil der Mahlgemeinschaft, die im Gedenken an ihn zusammenkam.

Eben der umfassende Handlungszusammenhang von Lebenden und Toten, der als ein Spezifikum der christlichen Memorialkultur anzusehen ist, bildete eine wesentliche Voraussetzung dafür, dass der Heiligenkult zu einer Schwächung der Sozialbeziehungen innerhalb der Gemeinden führen konnte. Durch die im Laufe des 3. Jh. stark akzentuierte Rolle der Heiligen als Fürsprecher und Interzessoren in Fragen der Sündenvergebung eröffneten sich für lapsi und vergebungsbedürftige Christen Bußmöglichkeiten, die nicht nur in formaler Hinsicht mit dem amtskirchlich kontrollierten Verfahren der paenitentia publica konkurrierten: Gegenüber der disziplinär und in ihrer Durch- 
führung in der Gemeinde verankerten Kirchenbuße akzentuierte die Annäherung an individuelle Interzessoren deren Mittlerstellung zwischen der göttlichen und menschlichen Welt und machte das Streben nach Sündenvergebung und Heil zu einer Angelegenheit, die außerhalb der Gemeinden und ihrer Kommunikations- und Handlungszusammenhänge gesucht werden konnte. Dies allein hatte jedoch nicht zwangsläufig eine Schwächung und Fragmentierung der sozialen Handlungsbeziehungen zur Folge. Vielmehr wirkten zahlreiche Märtyrer während ihrer Vorbereitung auf das Martyrium der Entrückung in eine Mittlerstellung entgegen, indem sie ihrerseits ihre Angewiesenheit auf die Fürbitte ihrer Besucher betonten und durch ostentative Gesten der Verdemütigung ihre Einbindung in reziproke Handlungszusammenhänge signalisierten. Ihren deutlichsten Ausdruck fand diese Haltung in den Refrigerien, den Mahlfeiern, zu denen sich die Besucher in den Gefängnissen mit den Märtyrern zusammenfanden: In ihnen wurden sozialethische Kommunikationsbeziehungen wirksam, die eine Einbindung der Märtyrer in die menschliche Handlungsgemeinschaft akzentuierten und das individuellen Streben nach Heil und Vergebung in Akte der Gemeinschaftsstiftung integrierten.

Die im Umgang mit den noch lebenden Märtyrern entstandenen refrigeria bildeten bis zum ausgehenden 4. Jh., als sie vor allem von amtskirchlicher Seite bekämpft wurden, zugleich eine bestimmende Form des Gedenkens auch an die verstorbenen Heiligen. Wie die bald nach den großen Verfolgungen der 250er Jahre entstandenen Graffiti unter S. Sebastiano verdeutlichen, wandelte sich dabei auch der Charakter der in den Refrigerien wirksamen Kommunikations- und Interaktionsbeziehungen. Im Unterschied zu den Mählern, die man noch wenige Jahre zuvor im Beisein der Märtyrer gefeiert hatte, fielen die Gesten der Verdemütigung, mit denen die Heiligen auf die ihnen dargebrachten Äußerungen der Verehrung reagiert hatten, weg: Sie wurden zu einseitigen Empfängern von vota, die eine zunehmende Distanzierung und Entrückung der heiligen Interzessoren aus menschlichen Handlungs- und Kommunikationszusammenhängen in Gang setzten.

Das fragmentierende Potential der Heiligenfürbitte begann sich erst unter diesen Voraussetzungen einer die Grenze des Todes überspannenden Handlungsgemeinschaft, die aber als solche nicht mehr unmittelbar sozial erfahrbar war, zu entfalten. Das Refrigerium löste sich aus den kommunikativen Handlungszusammenhängen, in denen es ursprünglich beheimatet gewesen war, und existierte unter veränderten Bedingungen weiter, in denen die Martyrien nicht mehr zum gegenwärtigen Erfahrungshorizont der Gemeinden gehörten. Die Mahlfeiern, die in der Triklia an der via Appia bald nach dem Ende der großen Verfolgungen in den 250er Jahren abgehalten wurden, sind Zeugen dieser Entwicklungsphase, die man - in Anlehnung an die Terminologie der kulturwissenschaftlichen Erinnerungsforschung - als Übergang von 
einem kommunikativen in ein kulturelles Gedächtnis bezeichnen könnte. ${ }^{155}$ Auch wenn die Refrigerien - ebenso wie die Martyrien selbst - in Zeiten der Verfolgung nie den Schauplatz einer „Alltagskommunikation“ gebildet hatten, waren sie Teil eines innerweltlichen Kommunikations- und Interaktionszusammenhangs gewesen, der in dem Moment, in dem sich das Heiligen- zum Totengedenken wandelte, nicht mehr gegeben war. Die Heiligen blieben zwar auch unter diesen Bedingungen unter ihren Verehrern gegenwärtig, doch das Gedenken an sie basierte nicht mehr auf sozial erfahrbaren Kommunikationsbeziehungen.

155 Vgl. dazu o., S. 7-9. 